No 22,1979

EXPERIMENTS WITH FISCAL POLICY PARAMETERS ON A MICRO TO MACRO MODEL. OF THE SWEDISH ECONOMY by

Gunnar Eliasson 


\title{
EXPERIMENTS WITH FISCAL POLICY PARAMETERS ON A MICRO TO MACRO MODEL OF THE SWEDISH ECONOMY
}

\author{
Gunnar Eliasson
}

\section{INTRODUCTION}

The Swedish micro to macro model was originally conceived as a device to study inflation at the micro market level and the relationships between inflation, profits, investment, and growth.* To accomplish this, we needed to specify the decision process at the firm level. A realistic short- and long-run supply determination of the individual firm was considered necessary. We needed explicitly modeled market mechanisms rather than rigid aggregation functions only. In fact, the micro to macro approach would make very little sense without an explicit market process. We needed quite elaborate short period-to-period feedback links thorugh the markets to picture price-volume interactions. Finally, we had to bring everything up to the macro, national accounts, level for three reasons:

1. The complete micro to macro data-base system had to be consistent at the macro level. For this, substantial modifications of existing macro data bases assembled by the Swedish Central Bureau of Statistics were necessary. Lack of complete micro data information required that we fill in the holes with "synthetic" information in the form of "chopped up" aggregates.

2. Since we have had to gather the micro (firm) data ourselves, we have begun with a $100 \%$ synthetic firm micro data base that adds up to correct totals to get a head start with both experiments and calibration (we prefer that term to "estimation") of the model. This synthetic data base is being gradually replaced by realfirm data for completing the model.

3. Some important test variables will be historic time series on macro aggregates, like GNP, industrial investments, and others (see tables 2.3 and 2.4).

With this model properly set up, one will find that it is possible to study problems other than the ones mentioned above. More particularly we have added two quite general objectives: to study the "conflict" between short-term allocative efficiency and the stability of the entrie system (or long-term efficiency), and to study the effects on industrial structure from exogenous influences such as relative price changes in world markets and technology changes.

Short-term allocative efficiency refers to the speed at which volume adjustments occur in response to market price signals. Long-term efficiency or stability depends upon how reliable these short-tem market signals are for long-term decision making and/or how they are corrected and interpreted by individual firms, especially in the context of investment decisions. It follows that the more orderly is market price formation, the more reliable are price signals. However, the ups and

*The project would have been impossible without the generous back up of technical skills from IBM Sweden, a partner in this research venture.

Several persons have been actively involved in this project at various times. In particular I would like to mention Gösta Olavi, IBM Sweden, who has provided indispensable and efficient support on the mathematical and programming side, as well as Louise Ahistrom and Thomas Lindberg, at IUI, who have been responsible for putting together and adjusting the data base to the format of the model. 
downs in relative and absolute prices in the model depend on volume responses to past relative and absolute price changes and other factors. We will be able to watch the consequences of this when we replace the Swedish payroll tax completely with a value-added tax in one of the experiments to be reported on below.

Structural changes in the micro specified sectors occur endogenously in response to relative price changes in the sense that a number of efficients in a corresponding macro model, like capital and labor elasticities in the production function, export price elasticities, and so on, would not be constant.

The empirical part of this paper, which reports a series of experiments on tax parameter changes, will illustrate part of this potential. Before this, however, we will give a verbal and diagrammatical presentation of the entire model. Emphasis is placed on the handling of the tax system in the model. We will also give some statistical highlights of the Swedish tax system.

\section{THE MODEL}

At the macro level the Swedish micro to macro model appears as a 10 -sector, quarterly Leontief-Keynesian system, complemented with a quite sophisticated household (nonlinear) expenditure system with habit formation and saving being determined simultaneously with overall spending. ${ }^{1}$ A macro monetary sector is fully integrated with the rest of the model. Four of the 10 sectors hold a number of individual firms, which compete with one another in the product, labor, and money markets.

Over time the economy operates under a "soft" exogenous, upper technology constraint. New, superior technology is brought in by way of endogenous investment. Hence economic growth is endogenous. Rates of return of individual firms, determined endogenously, are key variables in determining investment and growth.

Two basic ideas underlie this project. First, we are not interested in predicting more detail. Our concern is with understanding behavior at the macro level in the first place. We believe that more micro information is called for to explain macro behavior properly. Hence, we also need to study and to know the covariance structure of our micro units (firms), especially when it comes to getting our micro specifications right. We expect a realistic micro-founded model to possess macro properties that are not exhibited by conventional macro models. If we think our assumptions are right, we should put a corresponding belief in the realism of these unconventional properties. Right or wrong is a genuine empirical question, and the only truly scientific response to it is to go out and check. ${ }^{2}$ The reader will have to opportunity to decide for himself as he proceeds.

Second, we believe that entering more information by more detailed breakdown of sectors tends to cut across decision units in a very arbitrary way and very soon meets with impossible problems in statistical measurements. Rather, we have opted for choosing the decision unit (the firm) as the economic agent and the observation unit. This makes it possible to model market processes explicitly at the micro level and to join micro and macro theory in a very natural way. Above all, however, this approach opens up a wealth of high-quality statistical micro in. formation for direct use in improving our understanding of economic phenomena at the macro level.

${ }^{1}$ A complete mathematical specification of an earlier simpler version of the model and a partial mathematical write-up of the model used here are found in Eliasson (1976b),

${ }^{2}$ This means that the next stage of model development will be predominantly devoted to enlarging and refining the micro data base. See below. 
The micro firm model is a generalized planning-realization model that is a combination of the well-known Cyert and March (1963) and Modigliania and Cohen (1961) models and some earlier elaborations of these ideas by myself (Eliasson, 1969). It also draws heavily on empirical information on business economic planning systems in U.S. and European firms (Eliasson, 1976a). If the firm model is simplified far enough it collapses into the classical model of one firm that is a unit with one production function facing a set of prices given from the outside. One novelty in this model is that the actions of all firms together in labor and product markets determine prices in a sequential manner. Since the model cannot be solved for these prices each period, there exists no equilibrium position of the economy where all firms have edged themselves into input-output combinations where marginal conditions are fulfilled. Rather, if they try too hard or if the market pushes them too hard (i.e. if the market allocation mechanism is too fast and efficient), the system becomes unstable.

On the output side the model simulates life cycles of individual firms (production, employment, prices, wages, profit and loss statements, cash flow balances, balance sheets, etc.) according to the definitions we prescribe. On the production side there is a complete GNP breakdown on 10 sectors with an explicit aggregation from micro to macro in the four sectors inhabited by real firms. There is also a conventional breakdown of the GNP components from the demand side. All real transactions are traced on the money side and complete financial accounts are printed out for control purposes. At this time financial flows do not yet exert a feedback effect on the real side through an endogenous interest determination and/or through financial "quantity" constraints.

The model as it now stands can be loaded with data from any industrialized country $^{3}$ provided the statistical information required at this stage is available and provided some primary production sectors like agriculture do not play a heavy role in the economy. To explain how close to or how far from a representation of Swedish reality we are, we have to be more explicit.

\section{Macro System}

Figure 2.1 exhibits the macro flows of the model as it now stands. The production system makes up the center of the diagram. The four sectors RAW, IMED, DUR, and NDUR (see notes to Figure 2.1), are inhabited by individual firms in a way to be described in the next section. These sectors account for most of industrial output. Of the remaining sectors, the service sector and the government sector are indicated by $Z$ and GOV respectively and are treated as ordinary macro input-output sectors in the model. Five additional input-output sectors are explicit in the same way in the model. These sectors-agriculture, mining, oil, construction, and electriciy generation-are all placed in the box OTHER production. Output in these sectors is endogenously determined in an indirect way through total demand (i.e., there is no capacity constraint), exhibited to the right in Figure 2.1.

Total demand is determined by wages and salaries and dividends and soon in the consumption or expenditure system from the left in the upper part of the diagram. Total production is added up at the bottom of the diagram and the total system, finally, is supplied with imports from the left-hand part. The import and export rates of each market move over time in response to the domestic and foreign price differentials. At the export side this takes place at the level of the individual firm (see below). 


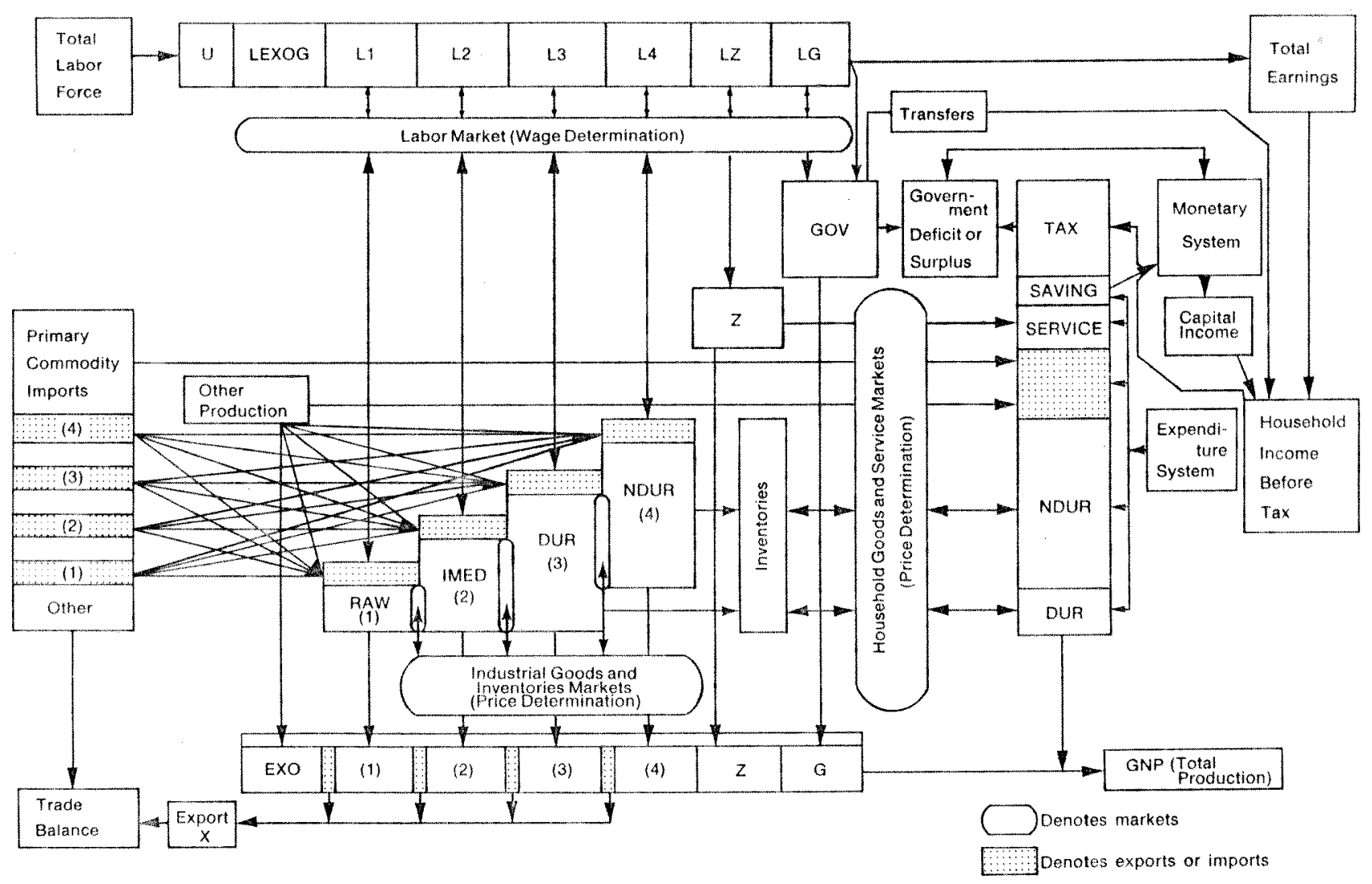

Figure 2.1. Macro delivery and income determination structure of Swedish model. Sectors (Markets): 1. RAW = Raw material production; 2. IMED = Intermediate goods production; 3. DUR = Durable household and investment goods production; 4. NDUR = Consumer, nondurable goods production. 
There is an explicit micro (between firms) labor market (upper part of Figure 2.1) and an explicit product market between firms and between firms and households (middle and left-hand part of Figure 2.1). The market processes are explained in more detail below.

Total household demand is determined in a macro Stone-type expenditure system with a Friedman-type permanent income specification by adding up (a) wage payments in each individual firm; (b) wage payments for each of the other production sectors: (c) transfer payments; and (d) capital income. Then, income taxes are

subtracted to get disposable income. In this expenditure system, saving is determined simultaneously with consumption. There is a nonlinear tradeoff over time between saving and purchases of household durable goods in which the real return to saving and the unemployment situation play a crucial role. Furthermore, the household savings plan is guided by a desire to maintain a certain real cash balance, determined by household income and modified by the situation in the labor market (precautionary motive) and the real rate of return to saving. Space does not allow us to present more detail here. ${ }^{4}$

Government demand is indirectly exogenous in the sense that government employment is entered exogenously. We then use the share of total government purchases and final demand from the Swedish input-output tables to derive total government demand. We should observe here that the government includes state and local governments. It also includes the obligatory, supplementary pension scheme, a circumstance that is of importance for the tax experiments to be reported on below. In this sense the government sector includes what in Sweden is called the "consolidated public sector."

The tax system will be described in more detail below. The model is planned to include a monetary system in the near future. The empirical applications reported below do not incorporate monetary effects. For this reason we abstain from presenting the monetary sector here.

\section{The Firm Decision Model (Micro)}

The novel part of this model is the business-firm sector and the way it combines through markets with the macro structure. In this section we will give a brief presentation of the individual-firm model. To a large extent it draws on an earlier interview study of business planning practices (Eliasson, 1976a).

Each of the four markets holds a variable number of firms. The data of all firms add up to the total from Swedish national accounts statistics. This means that after "real" firms have been entered into the data base, there always remains a dummy in each market (the difference between the market total and the sum of firms). This dummy either remains and is treated as one firm or is split into several synthetic firms (see later paragraph on data base).

For the time being there is only one price in each market. We have entered this simplification for practical reasons. There is no way to collect price data on the products of individual firms. This means that firms technically compete with one another with their profit margins. ${ }^{5}$ In the labor market, on the other hand, wage levels can differ among firms. We assume, however, that labor is homogenous. Until labor input has been made heterogenous at some later phase, this means that each firm has its own homogenous wage level each period and that uneven income distributions for micro specified sectors, that can be reproduced for each period if we

\footnotetext{
The reader is referred to Fliasson (1976b).

${ }^{5}$ We plan to enter explicit market imperfections at some later time.
} 
so wish, depend on a slow and imperfect labor market arbitrage.

Figure 2.2 gives a view of the individual-firm model. At starting time, each firm is initialized with its own set of historical data and a set of data that describe its position at a point in time referred to as the positional data matrix. We call this process "initialization," as displayed on the left-hand side of Figure 2.2. The historical input vector consists of sales, market prices, wages, and profit margins.

In the EXP module, historical prices, wages, and sales are translated into expectations for the next year and the next quarter. Price and wage expectations only serve as a first trial step in the search for a production plan each quarter.

Similarly, in the profit-targeting module, historic profit margins are translated into profit-margin targets for the next period. Profit targets can be revised from quarter to quarter. We have, however, entered the predominant practice among firms to try to stay within their annually budgeted profit targets throughout the budget year by making revisions very slowly. Similarly, profit targets are modeled to change quite slowly from year to year, while sales, price, and wage expectations may shift more rapidly in response to sudden changes in exogenous variables.

We have used conventional smoothing formulae with linear and quadratic error correction devices in the expectations and profit-targeting modules. The quadratic correction has been entered to allow for a tendency to risk aversion in markets where prices fluctuate a lot. ${ }^{6}$ These modules have presented many problems in numerical specification. In the long run, however, we hope to be able to draw directly on internal firm data for a subsample of firms.

The firm model has deliberately been designed to mimic internal planning processes in a business firm. The use of profit-margin targets based on historic profitmargin targets based on historic profit-margin criteria for instance reflects frequent business practice. The stepwise decision sequence in Figure 2.2, furthermore, very much captures the iterative planning-realization-reporting round of the budget process. The model exhibits the common method of not carrying the iterations around several times each period to approximate profit maximization but rather stopping when profit margins compatible with long-term profit performance of the past are met. Another typical feature is to conclude the planning sequence at the left-hand side of Figure 2.2 with an internally inconsistent decision (budget) to be "corrected"

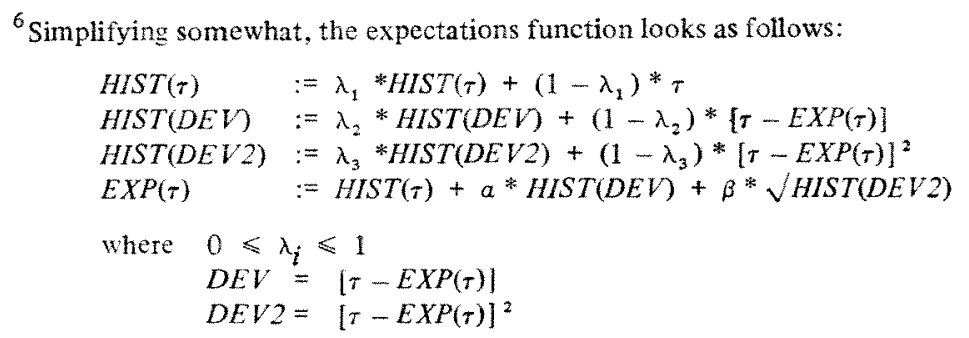

* represents a multiplication sign, and $:=$ is "make equal to" in Algol. Expectations on $\tau$, called EXP, are generated out of the firms' own formulae combined with a quadratic learning function.

So far we have tried once to estimate some of the individual firm coefficients above and several other coefficients by direct interviewing of executive staff people in one very large Swedish firm. The results tumed out very successful in terms of improving historic tracking performance of data for the same firm. Further efforts of this kind are currently planned. To this has been added the possibility to impose an exogenous adjustment of expectations in individual firms. The profit-targeting function is very similar to (1). The possibility of adjusting targets exogenously has also been added here as well as a device used sometimes in formalized profittargeting systems in U.S. firms, namely always to raise targets slightly above what has been arrived at in the budgeting process (the maintain or improve Principle, MIP) (Eliasson, 1976a, $236 \mathrm{fn}$. For further detail on specification see Eliasson (1976b). 


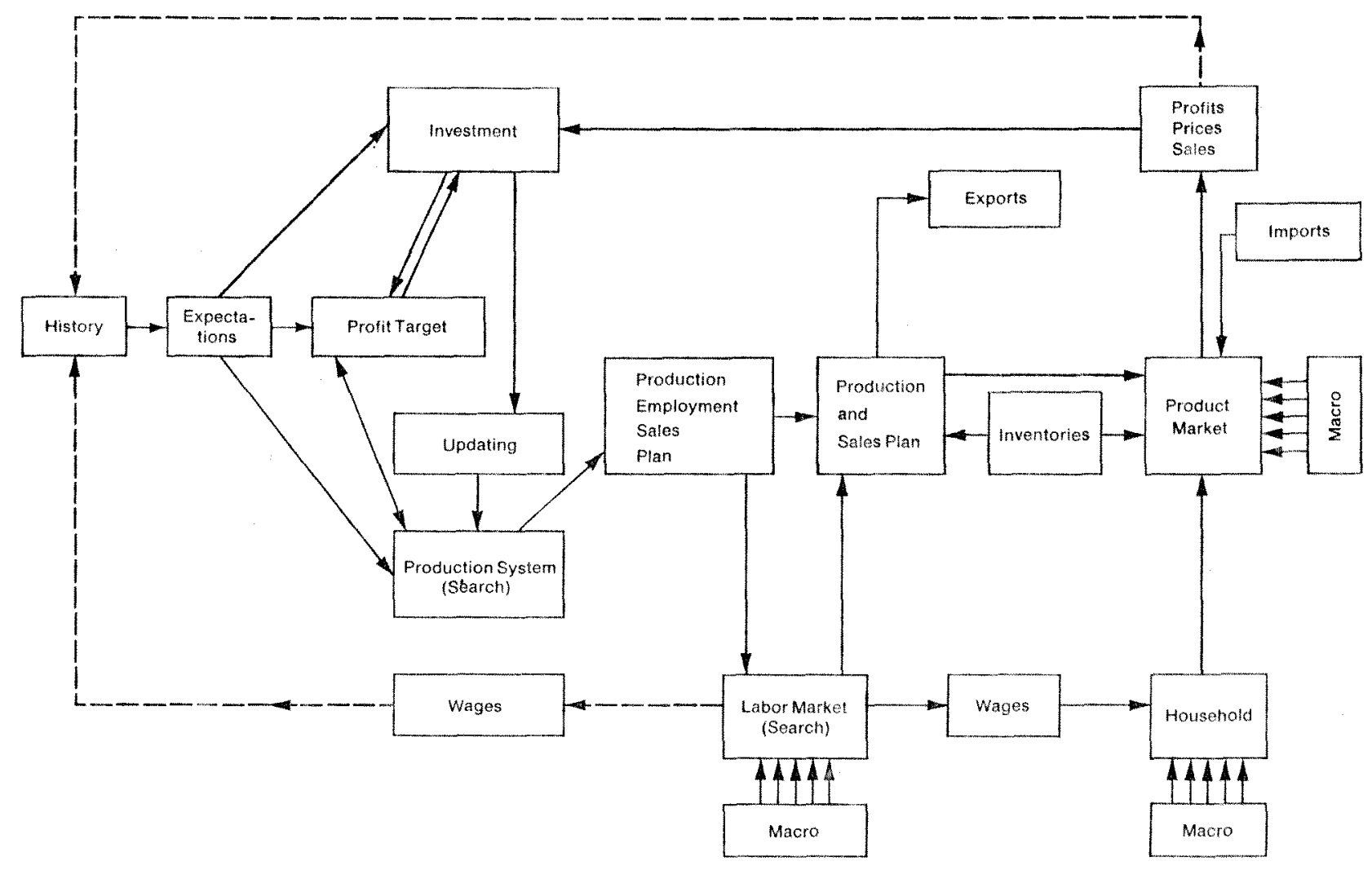

Figure 2.2. Business decision system (one firm). 
in the realization phase or the next planning round. ${ }^{7}$ The profit-margin target replaces the profit-maximizing assumption when it comes to determining, among other things, the output volume each period. The model allows a grading of the intensity by which the firm tries to improve its profit position each period. We can, if we so wish, approximate profit-maximizing behavior in a static sense by pushing up margin targets above what has been historically accomplished under the restriction that expected profits in each firm, in money terms, each period (quarter) do not diminish. We cannot, however, solve the system for maximum profits. It is important to note here that the "maintain or improve profit-margin principle (MIP)" that we apply gives rise to firm behavior that is often quite similar to, but also sometimes substantially different from, that of the maximizing firm. ${ }^{8}$

Price and wage expectations are fed into the individual firm production system, illustrated in Figure 2.3. Each firm is placed somewhere within its individual production frontier, that is a function of effective labor input $Q F R(L))^{9}$ Sales expectations determine the first step only. Each firm undertakes to search each quarter for a new labor input and output combination that satisfies its profit targets.

It would again take too long to describe in detail how this search goes on. Suffice it to say that there has been an effort to mimic the stepwise tradeoff that takes place between the sales, production, and the controller's departments in a firm before a short-term plan is reached, as described in an interview study of 60 firms that has stretched over more than 5 years (Eliasson, 1976a). One feature, that to my knowledge is very realistic and should be there is a "soft" upper capacity constraint (not shown in Figure 2.3). When under unusually tough market pressure, firms can "try harder" (within a limit) and raise productivity in order to maintain profit targets as described above. When the firm has found a satisfactory labor inputoutput combination based on expected prices and wages, it has a provisional recruitment plan and searches for additional labor in the labor market or it attempts to lay off labor (see below).

The production frontier $Q F R(L)$ in turn shifts from quarter to quarter owing the new investment and depreciation of old output capacity. There is a volume and a quality aspect to investment. Simplifying somewhat, the volume effect moves $Q T O P$ in the diagram upwards, while improved quality (higher performance) of investments bends the curve (makes it more convex). Improvement of the quality of equipment is determined by an increase in labor productivity of new investment over the productivity for the vintage investment of the period before. This rate of increase is entered exogenously by assumption and constitutes the technology constraint. New technology is entered through new investment and old equipment. (measured as potential capacity in each firm, QTOP in Figure 2.3) depreciates at an exogenously determined rate. "Average technology" is a weighted average of past and new technology and determines the curvature of $Q F R(L) .{ }^{10}$ All this takes place in each firm in each quarter.

\footnotetext{
${ }^{7}$ See further in Eliasson (1976a, especially chapter 9 and supplement 6 ).

${ }^{8}$ See the discussion in Eliasson (1976a, pp. $236 \mathrm{ff}$. and pp. $258 \mathrm{ff}$; and 1977).

${ }^{9}$ To see how $Q F R(L)$ is determined, see the paragraph on the data base below.

${ }^{10}$ Capacity to produce is expressed in terms of $Q F R(L)$ in Figure 2.3. Roughly speaking, new technology enters through an exogenous upgrading of $\lambda$ (see Figure 2.3) by merging the old and the new (additional) $Q F R(L)$ through an harmonic average. We prefer to work with a production system with capacity expressed as potential output and no explicit aggregate measure of capital stock. The reason is that the estimation procedure is geared to direct use of individualfirm data on the format of each firm's own internal accounting and planning system. There one seldom or never meets with the concept of aggregate capital stock (see Eliasson, 1976a). The mere fact that $Q F R(L)$ shifts by investment of course means that one can define a measure of capital stock in terms of our system. If we do so, a somewhat generalized CES-type production function can be shown to appear (see Cliasson, 1978, pp. 63-65).
} 


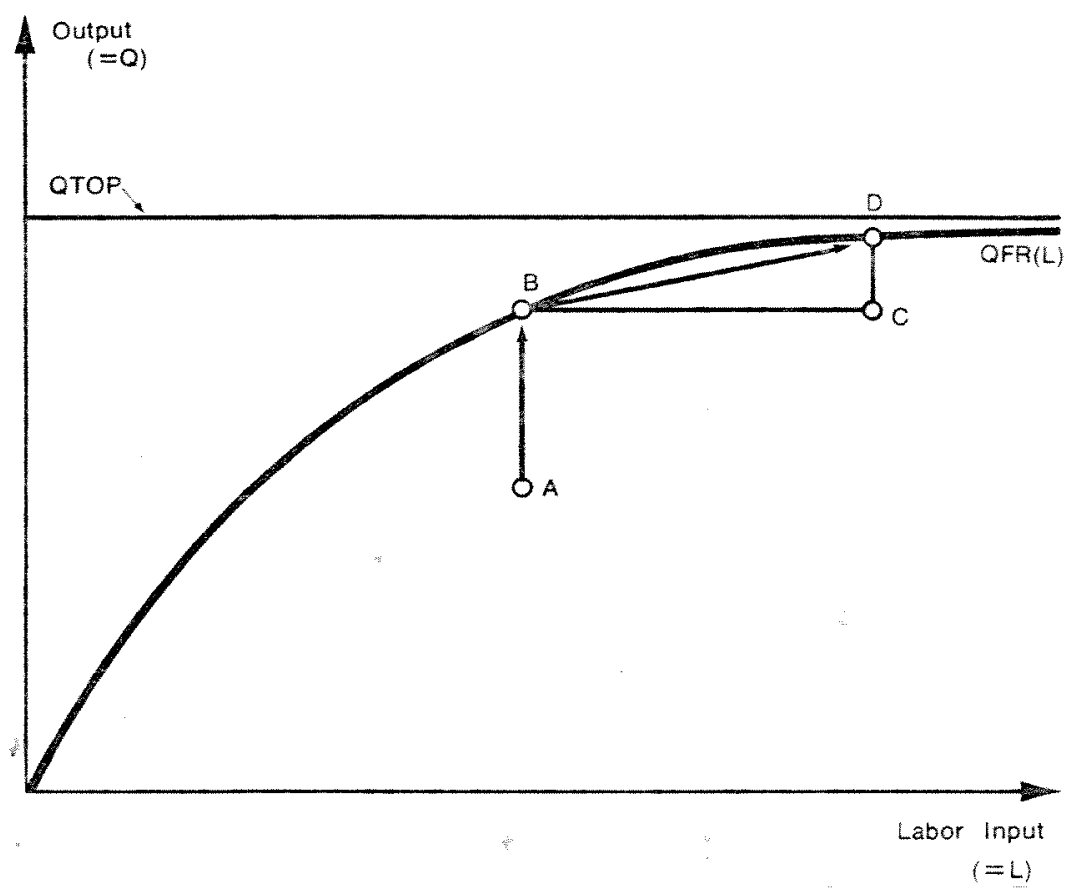

Figure 2.3. Production system (one firm). The function describing the production system of one firm at one point in time is $Q F R=Q T O P \cdot\left(1=e^{-\gamma L}\right)$. How this function is estimated and how it shifts in time in response to investment is described in Eliasson (1976b, chapter 4) and in Albrecht (1978b).

Investment is determined by a profit plow-back formula, complemented with a propensity to borrow that depends linearly on the difference between the nominal interest rate. Total cash inflow so determined, net of mandatory claims on finance from dividends and current assets, defines the potential investment budget. Actual investment spending is adjusted downward from this upper limit depending on the degree of unused capacity. This is fairly straightforward and needs no further explanation here. ${ }^{11} \mathrm{We}$ are planning to formulate a more intricate long-term investment planning-financing model that is compatible with the present structure of the rest of the model but is more in keeping with the planning format of individual firms. Since this is not yet ready we do not describe it here. ${ }^{12}$

${ }^{11}$ It is based more or less directly on a generalized version of the Meyer and Kuh (1957) residual funds-accelerator theory as formulated and estimated in Eliasson (1969).

${ }^{12}$ This part is designed but not coded. See Eliasson (1976b, chapter 3). 


\section{Markets}

Once production search is terminated, the firm has a preliminary production and recruitment plan. It lays off people if the plan says so or enters the labor market in competition with all other firms (Figure 2.2, middle, bottom). Each firm can get what it needs or less, and the production plan has to be revised downward accordingly.

In the process, wages have been determined in the labor market. Firms search randomly within a more or less restricted market domain. If they find the pool of unemployed, they get what they need at their offering wage (a fraction of the expected wage increase). If they raid another firm, both compare offering wages and one of them has to adjust partially its wage level. A raiding firm offering a higher wage level gets what it demands up to a limit.

Wages feed into the household demand system and affect total product demand as described before.

In the middle of Figure 2.2, the production plan is transformed into a sales plan. Part of sales are channeled off to foreign markets, the fraction being dependent upon relative foreign/domestic price differentials.

After each firm has checked its final goods inventory situation to see to what extent it deviates from desired levels, it presents households (together with other firms in the market and import ompetition) with a price-volume offer of its products. Offering price in the first round again is based on the expected price.

Competitive imports flow in at a rate (of total supplies) that depends on the relative foreign/domestic price differential. Households respond by telling how much they want to buy at the offered price and trading goes on for a while. Households calculate their expenditure pattern at each offered relative price vector via the household demand system. Firms check against their individual profit targets to decide how much they will charge to supply these volumes. After a predetermined number of iterations prices are set, and firms adjust their volumes and inventories. Quarterly prices, profits, and sales flow back leftwards in the upper part of Figure 2.2 and wages flow in the lower part, all are then incorporated as historic data. A new quarterly round begins.

At each period, endogenous prices can be used as weights to compute an aggregate volume index. Similarly, in each period endogenously determined volumes can be used as weights to compute an aggregate price index.

\section{Summing Up}

It is impossible to explain ali the algorithms of the model here ${ }^{13}$. To illustrate, let us define a subset $[\Theta]$ of endogenous variables (micro or macro) that we are interested in, say those macro variables that are studied in the tax experiments and listed vertically in Tables 2.3 and $2.4(W, P D O M, M, \ldots)$.

Each of these variables chosen (and others as well) can be represented by a very general function.

$$
\Theta=\Gamma(X) .
$$

This function is very complex and is not at all well behaved. It is generally not continuous and differentiable. Most of the theoretical and empirical work of this pro-

\footnotetext{
${ }^{13}$ For this the reader is referred to Eliasson (1976b).
} 
ject consists of ascertaining the properties of $\Gamma$ at various points in $X$ space. This work is now going on and its empirical side will dominate the next phase of the project (see below). To get a feeling for the properties of $\Gamma$ let us divide $(X)$ into subsets of variables:

$X 1$ : hierarchical ordering of algorithms, illustrated diagrammatically in Figures 2.1 and 2.2.

$X 2$ : structural (technical) parameters. Macro parameters and identities. Coefficients that are kept constant throughout simulation or are varied exogenously.

$X 3$ : time reaction parameters ${ }^{14}$ (measuring how the individual firm transforms its price, wage, and sales information into expectations, how fast it changes its exports ratio in response to foreign-domestic price differentials, how it reacts when raiding or being raided in the labor market, how it determines its offering wages and prices, the number of searches it is allowed in labor and product markets, and so on (in ali 20 parameters).

$X 4$ : starting positional data matrix (micro and macro). Exogenous.

$X 5$ : historic input matrix. Exogenous until starting time.

X6: policy parameters (e.g., the nominal tax rates to be experimented with in this paper).

$X 7$ : other exogenous input variables.

The $\Theta=\Gamma(X)$ structure of the model is graphically illustrated in Figure 2.4. If we look at one algorithm, at one particular point in time, we will find that most decisions in the model respond directly to classical expected price differentials (market disequilibrium) leading to an expected improvement in business profits in the short run as well as in the long run, that will be realized ex post, if not countered by aggregate market response. The general target of a business unit in the model is to maintain or improve its expected profit margin (MIP) position, and to stop responding when certain criteria are satisfied and/or when a certain amount of time has elapsed. These price-reaction functions are very simply expressed. But they are numerous, and when all interaction within a period (a quarter) is over most $\Theta$ will have become functions of most $X$ and past $\Theta$. This complexity is further increased when we move from period to period.

Hence the causal ordering of the entire system at the micro level $(X 1)$ is important to understand the entire model economy at work and the simulation results. The decision structure within the firm, as depicted in Figure 2.2, and the search order in the labor and product markets are most important. Profit targeting, for instance, has a strong impact on cyclical as well as long-run growth, properties of the entire system. Feeding back information from the employment or inventory parts of the system means less intensive enforcement of targets and results in very different behavior. Similarly, some simple experiments have shown that the way we loop together the sales planning, inventories, and product market blocks in Figure 2.2 can generate very different cyclical patterns. The core of the cyclical as well as growth processes of the model is defined by the links (over time and within Figure 2.2) between expectations and profit targeting on the one hand and wage setting in the labor market and investment determination on the other. Any change in the interlinking of these modules would strongly impact the behavior of the system. Perhaps the most illustrative example is when we close off labor market search between groups of firms or markets entirely. If relative product prices in foreign markets (exogenous) develop differently, a very uneven labor income dis-

${ }^{14} \mathrm{~A}$ computer algorithm to estimate these parameters is defined in Eliasson and Olavi (1978). All the $X 3$ parameters are listed and described there. 


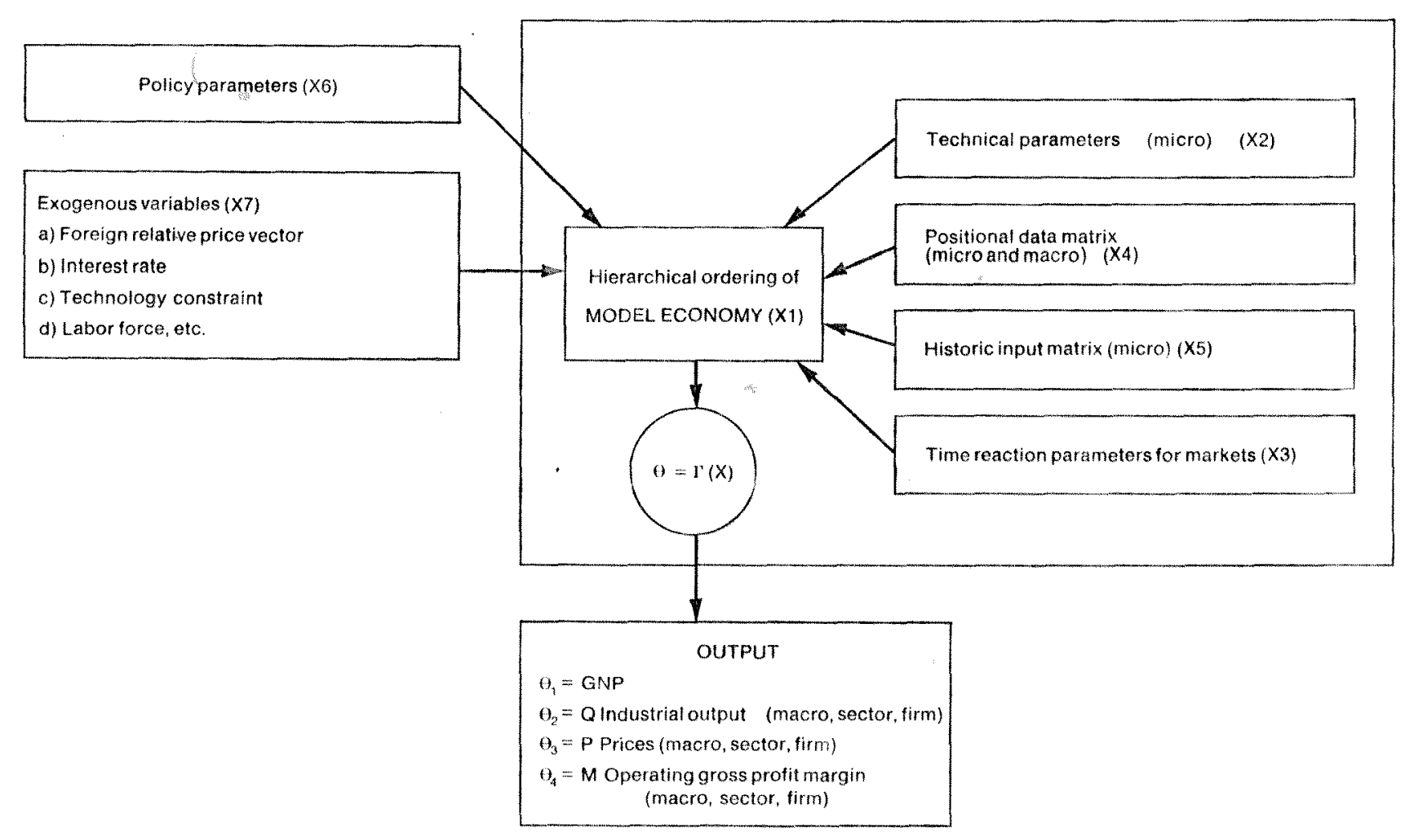

Figure 2.4. Ordering of variables, policy parameters, and coefficients of entire micro to macro model. 
tribution soon develops between close-off sectors, and profit as well as total growth patterns changes significantly. This "theoretical" property alone emphasizes the importance of the market pricing process in the behavior of total economic systems and the need for more empirical research in this area. On the internal planning and decision structure of the firm the empirical specification is as well founded as it can be, owing to a 5-year interview study (Eliasson, 1976b) that preceded this project and that has strongly influenced the design of the firm model. On the market side the availability of relevant, systematized information is embarrassingly scanty. This means that an effort to become more knowledgeable about wage setting and mobility in the labor market at the micro level is planned and will be designed on the format of the model.

\section{The Tax System and the Public Sector}

Figure 2.5 shows how the public sector interacts with the rest of the model via its taxes, transfers, spending, and borrowing (lending).

Firm profits are taxed at the individual firm level and we apply calculated effective tax rates to account for Swedish fiscal depreciation rules. Likewise the payroll tax $(W T A X)$ is applied as wages are paid out. We here use the nominal rates on a properly specified tax base.

Similarly the value-added $\operatorname{tax}(V A T A X)$ is applied at the going rate when the households purchase goods.

The problem of relevant specification refers mainly to the income tax (ITAX), and its progressiveness, as well as to transfer payments (TRANS). The model is equipped with a macro income tax function estimated by a simulation method in

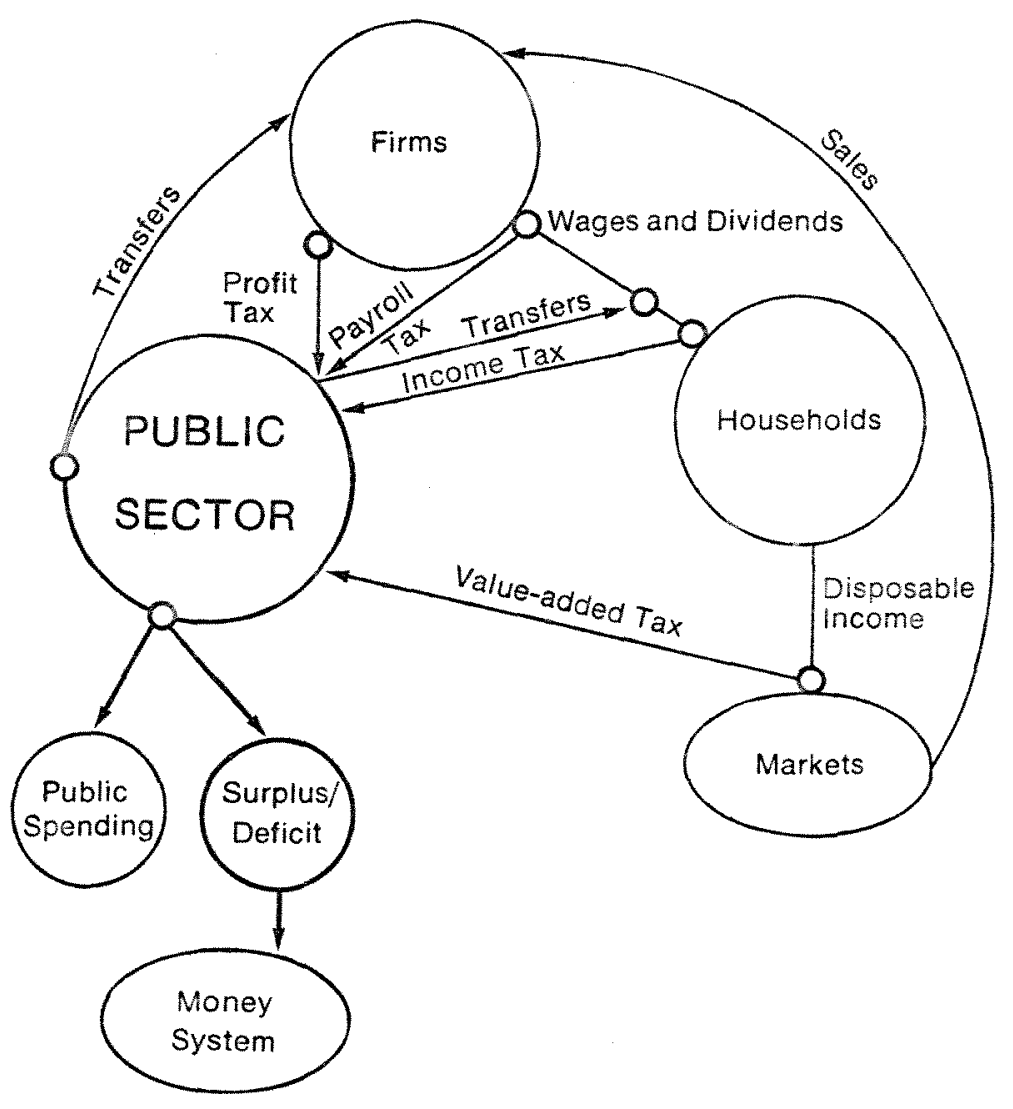

Figure 2.5. Tax system. 
the highly disaggregated tax model developed by Jakobsson and Normann (1974). The tax rate function is of the following form:

$$
T X I=\frac{I T A X}{L^{*} W}=A \cdot W^{e \cdot 1},
$$

where $L$ is the number of taxpayers; $W$ is average "total" income; $A$ is a tax parameter (exogenous); and $e$ is a tax elasticity representing the degree of progression. ${ }^{15}$

With these notations the average income tax paid will be $A \cdot W^{\mathcal{E}}$. By entering $A$ and $e$ exogenously for each year, the fraction $T X I$ of income paid as income tax will depend on how much income is endogenously generated in the model. Hence, varying the value-added or payroll tax or the TRANS rates will exercise a feedback effect on total household income both through the whole economic system and through the ITAX function above. ${ }^{16}$

Similarly TRANS payments are entered exogenously as a fraction of total public expenditure. It should be noted here that in Sweden some transfer payments are subject to income taxation (e.g., pensions), and some are not. We disregard this and apply a uniform income tax rate on all taxable income each period. All transfer payments are treated as taxable income in the model to keep detail within limits. It should not affect the empirical results to be reported.

We should also remember that the public sector includes the large obligatory, supplymentary pension scheme, which means that payments to and from the pension (ATP) fund are treated as payroll taxes and transfer payments respectively. TRANS also includes unemployment compensation, assumed to be $60 \%$ of the current average wage and available to all unemployed.

To give the reader an idea of the dimensions of the Swedish tax world, Table 2.1 presents the financial relations of two families with the public sector in 1969 and 1975. In both cases there are two children and only one income earner. We have chosen the average income of a skilled (male) worker and a well-paid salaried worker with a before-tax income about twice that of the worker.

${ }_{16}^{15} \mathrm{e}$ can be written $e=\frac{m}{t}$, where $m=$ marginal tax rate and $t=$ average tax rate.

${ }^{16}$ An inconsistent experimental design that we enacted by mistake illustrates some macro properties of the model system quite well. The scales of the Swedish income tax system are not indexed. During inflationary times like the 1970 s absurd things occur if the scales are not frequently adjusted. This has been done several times since 1970 . The inflation rate is endogenous. These corrections (in the model) have to be entered through $e$ in the above TXI function. We forgot to enter such a correction after 1976 in a 20 -year experiment that started in 1968. A gradual slowdown in total economic growth occurred; not extreme, but unexpected, and it led us to look for the reason. We found a rapidly decreasing current, after tax income inflow into the household sector, and a tremendous public budgetary surplus piling up and being deposited in the money system. (Public employment and expenditures were fixed in volume terms.) Household private consumption was still being maintained at high levels but at a diminishing growth rate. Why? Households were simply borrowing back the public surplus at the going interest rate to maintain their living standards. In the current version of the model the only hindrance to borrowing is the upward drift in the interest rate that occurs if total demand for funds grows faster than total supply of funds. Interest costs are fully tax deductible in the model as well as in Sweden. The slight slowdown in growth in private consumption was dictated by the permanent income or habit-formation part of the household expenditure system that determines how fast households reduce their addicted consumption levels, that are in turn determined by past consumption levels. This reduction was strongly dampened by the efficient inflation and income tax hedge that borrowing constitutes in the Swedish tax world, a hedge that is also effectively enjoyed by income earners possessing highly valued and mortgageable property. This property of the entire model system was never thought of in advance. With the right set of assumptions one should, however, expect to find it there. 


\section{Data Base}

Even though fairly simple in outline, the model requires an enormous amount of data and numerical specifications by virtue of the number of micro agents. The full potential of the model in this respect will (for instance "tailor-made" parameter specifications of individual firms) not be utilized until far into the future.

All numerical specifications required by the model are more or less directly observable. All these needed data are not currently available. Since the start of the theoretical part of the project, however, a parallel data-base project has been going on that aims at gathering the necessary information eventually. The idea of this model has been to formulate it on the format of national accounts statisties at the macro level and internal accounting systems of the firm at the micro level. We believe that potential access to high-quality firm data bases and "technical" coefficients will compensate handsomely in the long run for our current estimating problems (see below). To run the model over historic time, however, we now lack large amounts of the required data, and substitute solutions have had to be resorted to. Also, some of the required data on expectations are currently not being collected. There is no good conventional method of estimating the parameters of the expectations functions, except by direct questioning of firms.

Table 2.1

Swedish Taxes (thousand Swedish Crowns ${ }^{\text {a) }}$

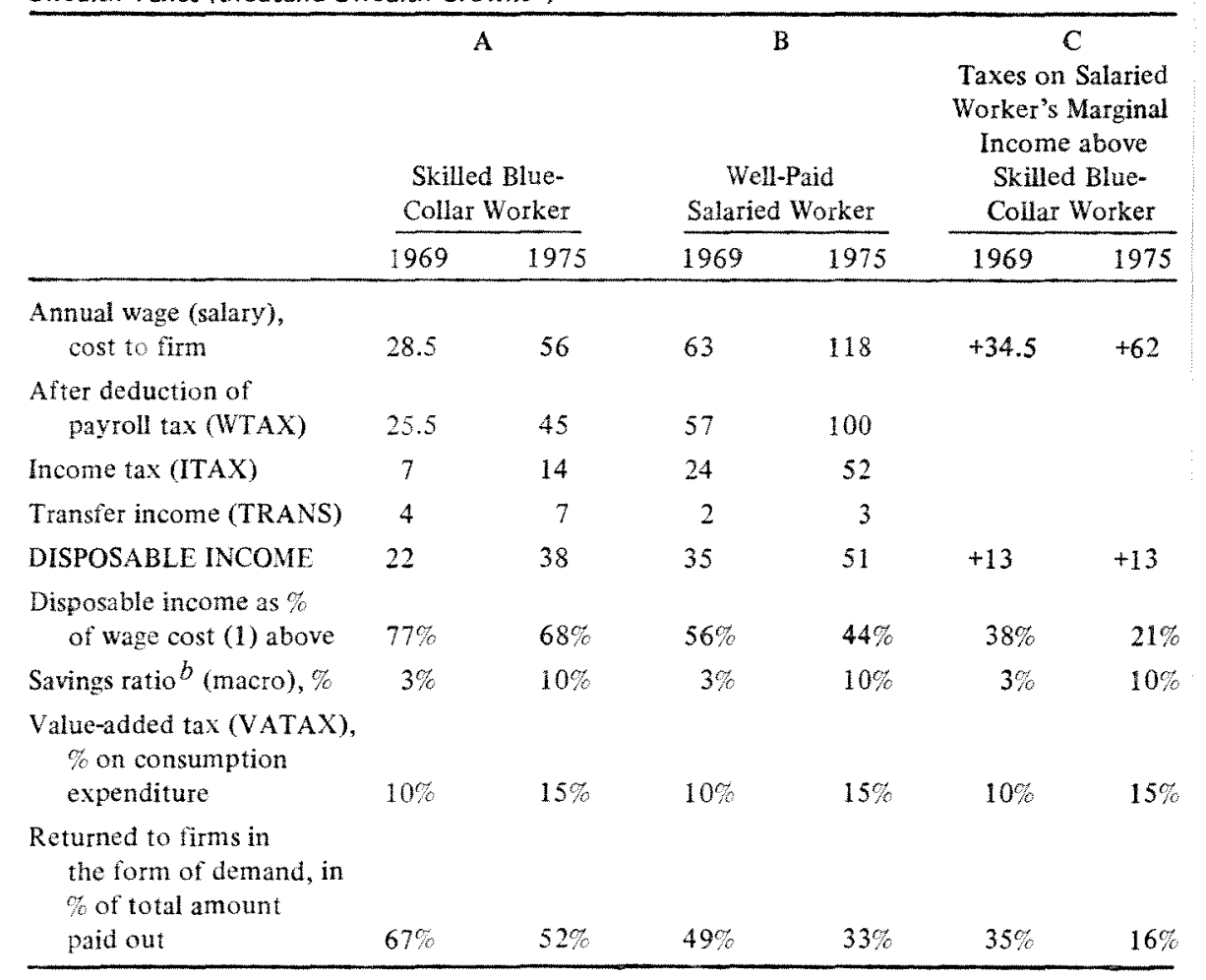

Note: Column $\mathrm{C}$ gives the same information as in the preceding columns but tax rates, etc., are calculated on the extra income the salaried worker earned above the skilled blue-collar worker, or $118-56=62$ thousand crowns in 1975 .

$a_{1}$ Swedish Crown $=\$ 0.21$ on January 24,1978 .

${ }^{b}$ The same average savings ratio for each year has been applied throughout columns A, B, and $C$. Savings data for different income groups or estimates on marginal savings ratios are not available. 
Parallel to the start of work on the model, a data-gathering process began. The annual planning survey of the Federation of Swedish Industries (Albrecht, 1978a) was designed on the format of the model in 1975 and in close contact with firms. We now have a 3 -year time series on a large number of individual decision units with more than 200 employees in Swedish manufacturing.

The sample consists of approximately 250 units that are "measured" each of the three years. Among other things this survey collects data on the coordinates of points $A, B$, and $D$ in Figure 2.3. This information allows us to approximate the production frontier $Q F R(L)$ at initialization for each firm. ${ }^{17}$ In a few years we should have enough time series data to estimate the relationships between investment and $\gamma$ and $Q T O P$ for individual firms as well.

A parallel project to collect a detailed data bank on the 40 largest Swedish corporations has been carried out at the Industrial Institute for Economic and Social Research (IUI). We will also be able to draw on two other IUT studies to handle the foreign operations of these firms. (Space does not allow for more detail on the micro data bases to be presented here.)

To be complete, we also need a matching and consistent macro data base to define the operating leveis of the model in terms of Swedigh national accounts statistics.

One thing that we have learned from work on this model is that a consistent demand and production measurement system is imperative for the proper functioning of a model with many linkages across firms and over time. It has been necessary to make substantial adjustments in the official Swedish statistics to obtain satisfactory consistency in this respect. ${ }^{18}$ We have found that high quality in the measurement system becomes imperative especially when we introduce interfilm markets and inventories with input-output coefficients entered exogenously. Such exogenous coefficients from official statistical sources have been found not to be consistent with the rest of the data base.

The macro data base has been prepared simultaneously with the model. This has not been possible for the micro data base. To be able to start experimenting with the model and to calibrate it against historic time series data, an interim synthetic firm data base has been put together. This data base currently consists of a very small number of real firms and split-up macro aggregate for each market. Whenever we have had the information on cross-sectional features, we have entered it. The experiments to be reported on below have been run on this mostly synthetic, micro data base that (for historic time) adds up to Swedish national accounts statistics supplemented with available cross-sectional information. On the estimating side, most of the parameters have been ascertained in the form of ratios from direct measurement. This goes for all the input-output coefficients. Each firm in one market has the same input-output structure on the purchasing side. ${ }^{19}$

The household demand system is a modified version of a Stone-type expenditure system (1954). We rely on somewhat modified parameter estimates on such a system on Swedish macro data from Dahlman and Klevmarken (1971). These parameters are entered as a priori hypotheses. The system has a habit-formation feature for each consumption category which very much rests on the same idea as the permanent-income hypothesis. A simultaneous handling of saying and stocks of consumer durables has been added as a novelty. It should be recalled here that modeling short-period change at the micro level rids us of a number of coefficients that normally appear in macro models. They are replaced by sequential orderings and feedbacks. The estimation problem centers on the 20 time-reaction parameters called $X 3$ and exemplified above. We will be able to estimate some of them for individual firms in the future by conventional econometric techniques.

\footnotetext{
${ }^{17}$ See Eliasson (1976b, p. 116) and Albrecht (1978b).

${ }^{18}$ See Ahlstrom (1978).

${ }^{19} \mathrm{My}$ experience is that firms do not have the kind of internal accounting system that makes direct questioning on their $1 / 0$ coefficients meaningful.
} 
For the time being, there is only one way to ascertain them-by trial and error experiments and checks against macro data (manually or by automated computer algorithms). ${ }^{20}$ It sometimes (not often) happens that we find double or multiple parameter combinations that satisfy test criteria, and we cannot discriminate between them, except by a prion judgment. This is very time-consuming work. (It is also true that an element of subjectivity enters in a more manifest way than is apparent in conventional econometric work. I would like to add as a personal note, however, that in large-scale modeling of this kind, experience and judgment should take priority over mechanical, statistical procedure, whenever possible.) It is easy to understand how important it is to have a high-quality and consistent statistical base to work from, since this data base contains most of the numerical specification that determines the properties of the entire model economy.

I believe that this should give the flavor of the current empirical status of model work. Much has been done, and the model, I believe, can give empirically valid answers to some questions. For the time being the model is capable of generating 5- to 20-year growth trends on real exogenous input data for a spectrum of macro variables with satisfactory accuracy as measured by closeness of fit $\left(R^{2} \mathrm{~s}\right)$, and not badly for sectoral change. It traces price, wage, and profit cycles well ${ }^{21}$ when run on real foreign price input for the various markets. We are currently somewhat uncertain about its capability of catching short-period (quarter-to-quarter and year-toyear) change well. We do not yet know whether unsatisfactory cyclical tracking depends on data-base inconsistencies at starting time (initialization), erroneous parameter specification, or lack of proper cyclical specification in some heavy exogenous input variables. ${ }^{22}$ One satisfactory feature of the model, however, is that the 20 parameters can be grouped into some that operate only (or roughly so) on long-term trends, some that affect cycles only, and a residual group that affects both dimensions. One additional piece of observational evidence, which is comforting as regards realism on the cyclical side, is that exogenous step impulses (not large ones) in exogenous variables and policy parameters tend to spin off gradually dampened 4- to 6 year cycles in the entire economy. This property also has a bearing on the experiments to follow.

TAXES, BUSINESS-CLYCLE POLICY AND INDUSTRIAL STRUCTURE: APPLICATIONS OF THE SWEDISH MICRO TO MACRO MODEL

\section{Properties of the Model}

We have chosen to present here a series of fiscal policy experiments on the entire model as described before, and more particularly those on the Swedish tax system. This should be of special interest for two reasons. First, the share of total resources taken out by the public sector ( $50 \%$ of GNP in 1976), which is partly used up and partly redistributed, is one of the highest in the world. This means that even minor modifications in the tax structure may have sizable effects upon the economy. Second, the very heaviness of the average tax burden raises particular problems of tax evasion and control. For that reason there has been an extensive discussion about modifying the tax system or even changing it drastically.

${ }^{20}$ See Eliasson and Olavi $(1978)$.

${ }^{21}$ An illustration of this will appear in the next 1978 English edition of the IUI Current Research Project Report.

${ }^{22}$ For instance, public transfer payments to the household sector have been entered as the average fraction of total public spending 1965-1975 each year due to lack of consistently specified data. Hence there is no policy cycle in public transfer payments and the corresponding cyelical impact is absent. 
We will study the effects on growth, inflation, and industrial structure of a shift in emphasis from one tax type to another. To keep the number of pages down we will limit ourselves to two tax categories, the value-added tax $(V A T A X)$ and the payroll tax $(W T A X)$.

We will carry out a sensitivity analysis to study the relative important of the two fiscal parameters. The simulation results will be compared with those of our current reference case, which tracks the growth paths of the variables studied 1968 . 1975 satisfactorily for this experimental purpose. The model has been loaded with the actual nominal tax parameters for the period 1968 through 1975 , and all fiscal and other economic data have been correctly and consistently entered at the micro firm level and at the national accounts level at starting time. We should recall that. numerical consistency throughout at starting time has been found to be a crucial prerequisite for the proper functioning of the model. We recall that the model forecasts historical, long-run growth trends of major macro variables well and prices, wages, and profits quite well both in the short and the long runs. We think that we can fairly safely say that the results indicate what would have happened to the Swedish economy over the 8-year period 1968 through 1975 if this or that fiscal measure had been enacted as described. We are, however, somewhat uncertain about the quarter-to-quarter effects and will not report such information except for illustrative purposes.

Recall again that the model, being a disequilibrium system, responds quite differently to policy measures or whatever exogenous disturbances it is subjected to, depending upon its positional description when this happens. This is a most desirable property. The problem is only to see to it that the data set that positions the model economy initially in 1969 and the exogenous inputs it runs on are consist. ently and relevantly specified. The year 1969 witnessed the recovery phase of a business cycle that peaked in 1970 .

There are three important systems properties that we should mention before we proceed, since they explain some unexpected experimental results. First, under normal circumstances most firms hoard labor to some extent (see Figure 2.3). This means that firms experiencing a demand increase can increase supplies and productivity simultaneously for a while. This is a very typical cyclical phenomenon from reality. Only on the production frontier does productivity decrease as more labor is recruited to work with less productive machinery (above $D$ in Figure 2.3). We have learned from model experiments that individual firms only seldom operate on that end of their production frontiers, and these experimental results seem to be sup. ported by preliminary evidence from the planning survey of the Federation of Swedish Industries. Second, we have mentioned that an exogenous step impulse tends to spin off a 4- to 6-year cycle in the model system. This means that the system will behave according to the Le Chatelier principle at least in some time dimensions. The initial effect in one direction will reverse itself through an endogenous counter-response of the system. These properties are conventionally assumed away in the mainstream of economic modeling: in Keynesian models through the absence of supply feedbacks and in neoclassical models through assumed perfect foresight or a fixed rate of return. The property arises in this model through expectations, a disturbed market price signaling system, and the effects on the rate of return on investment and capacity growth. Third, one particularly important instance of this property is that sudden, unexpected inflationary shocks (not necessarily large ones) 
tend to have a long-lasting downward effect on economic growth after an initial positive effect..$^{23}$ It is difficult to test for this property directly. So far my own attempts to ascertain its relevance ${ }^{24}$ have only turned out evidence in the affirmative. The property has been suggested by Professor Friedman in his 1976 Nobel lecture. Some econometric models report negative growth coefficients for the rate of change in the rate of inflation but this is too crude a test for the phenomenon we are discussing to be more than slightly helpful. Cagan's (1974) early report that common stock maintains its real value in the long run but that "stocks may take many years to catch up to an inflationary episode" (15 years is the median time in an international comparison) in fact refers more directly to the machinery in our model and hence is more supportive.

Throughout this empirical application we will be particularly interested in the effects of a fiscal parameter change on the absolute price level (inflation), total output, and the functional income distribution (profits and wages shares). ${ }^{25}$

We have defined most policy changes as a once-and-for-all step change throughout, and we allow the model economy to run for 7 years on that step input under the ceteris paribus assumption that firms are assumed to know about the duration of the policy when it has been enacted. For a short period like two or three years that is a reasonable assumption to make. However, over a longer time period, like 7 years, one may doubt the meaningfulness of the same assumption. For one thing, if bad effects are generated, a responsible govermment would enact new measures to counter them. This tends to make the ceteris paribus assumption somewhat strange for longer periods.

It is contrary to the logic of the model to reason in terms of a relative of absolute price change somewhere, assuming activity levels to be unchanged. A ceteris paribus experiment of this kind would break the core of the business decision system described in Figure 2.2 and would require the elimination of the labor and market processes. Such experiments simply cannot be run on this model, a specification that is strongly supported by reality. Period-to-period interaction between price and volume changes is not negligible, and, as mentioned, this very property tends to generate long-term systems results that are sometimes unfamiliar to persons drawing on their experience with more conventional macro models.

One problem that we have relates this dynamic feature to a persistent property of the model that appeared after the inter-industry market and inventory system was introduced into the model. Particular and temporary disequilibrium situations tended to develop here and there during simulation runs. Some of these disequilibrium positions could be interpreted as being "real" phenomena during the test period 1965-1975. However, most of our tedious calibration work has consisted in removing the cause of those temporary disequilibrium situations in the model that could not be interpreted as real ones. Our experience is that most of the bugs have been in the data-base input rather than among the parameters.

\footnotetext{
${ }^{23}$ These systems properties have been extensively investigated on an earlier version of the model in Eliasson (1978).

${ }^{24}$ Together with Dr. H. Genberg, Institute Universitaire de Hautes Etudes Internationales in Geneva. Some results will soon be reported. Also, of some earlier research on the rate of foreigndomestic price transmission in Genberg (1974).

${ }^{25}$ In analyzing these experiments I have been very fortunate in being able to draw directly on a recent IUI study (Normann and Sodersten, 1978) that includes a broad analysis of the Swedish tax system.
} 
The important aspect of this feature for our simulation experiments is that if we enact a policy change that pushes economic development in new directions, new temporary disequilibrium situations tend to show up at unexpected places, being dependent in turn on the structure of the initial data base. This has been especially so when parameter changes are large and sudden. Such situations in turn tend to spin off not only new 4-to 6-year cycles (as mentioned earlier) but cycles the amplitude of which cumulates for a while until the system settles back to nomal owing to an endogenous readjustment of the economic structure (the data base). The 7 . year period is not always sufficient to allow all this to happen, and our sensitivity analysis offers some examples of the importance of disequilibrium positions. We will furthermore see from the final, controlled experiments, when one tax system is gradually replaced by another and when effects tend to cancel from period to period, that the disequilibrium effects are much smaller. This time the long-term sevenyear experiment also makes more sense.

The numerical analysis on the model economy carried out so far tells us that when fed with a steady state exogenous input, total output keeps oscillating around an emerging steady state growth path. Similarly, the cycles generated by various shocks tend to fade away in the long run. This convergence is, however, very slow, and it depends critically upon the time it takes for profit rates to steady themselves. So far, however, the properties of the model in this respect have not been fully in. vestigated, and definite conclusions will have to await further analysis.

\section{Sensitivity Analysis}

In the first round we will analyze the response pattern of a ceteris paribus change in two fiscal parameters, one by one. These parameters are payroll tax rate (TXW); and value-added tax rate (TXVA).

The fiscal parameters above denote tax rates. Transfer payments in the model are to households in the form of various sorts of public benefits and total public expenditures for labor and purchases of goods and services. This is a macro variable. We do not distinguish between various categories of payments and the economic effects of changes in their composition. ${ }^{26}$ Transfer payments and such expenditures are in principle entered exogenously in volume terms. They will, however, be determined partially endogenously, since both wages and prices are endogenous.

This section on sensitivity analysis serves two purposes. For one thing it responds to highly topical questions referring to the power of payroll and value-added tax changes as countercyclical measures and to the absolute incidence of the parameter change. As regards the payroll tax in particular, this is a somewhat controversial issue. Second, this section serves a pedagogical purpose. We will tell what happens in the model step by step when we enact the parameter change. This way we will demonstrate, for instance, that the results are by no means apparent from one or two critical assumptions.

\footnotetext{
${ }^{26}$ This has been done in a recent study on a macro model of the Leontief-Keynesian type also developed at the IUI. See Dahlberg and Jakobsson (1977).
} 
Value-Added Tax (TXVA)

We first raised and lowered the value-added tax rate in 1969 with \pm 2.5 and 5 percentage points, respectively. Since the value-added tax rate was $10 \%$ on purchases of goods in 1969, the larger parameter change was a substantial one.

The effects of the increase in the value-added tax rate are quite straightforward. The experiment can be regarded as a case of restrictive fiscal policymaking. There is no corresponding feedback through increased public spending. There is a negative and not very large GNP effect that stabilizes at around $2 \%$ from the third year for parameter changes between +2.5 and 5 percentage points. (Figure 2.6 and also Table 2.2). Industrial output is affected similarly. The initial first year ( 2 nd and 3rd quarter) effects in Figure 2.6 depend on the habit-formation hypothesis embedded in the consumption system. The lowered purchasing power of households due to the increase in the value-added tax is buffered through less saving in the first round. It is interesting to notice that the two parameter changes result in output effects of similar magnitude (see Figure 2.6). In both cases, the employment level is back to. the initial level in year 7 (1975). The value-added tax rate increase (Table 2.2), furthermore, allows firms to push wage change (and temporarily employment) down, gradually realizing an improvement in the return to investment.

The surprise results come when we lower the value-added tax (expansive fiscal policy making). The first two-year effect on industrial output and GNP is up. The GNP effect, however, extends for a somewhat longer period. Consumers spend more, and especially on goods from sectors 3 (durables) and 4, owing to a higher real disposable income. However, some of the increased purchasing power of households in the initial phase leaks into increased savings and some into more imports.

In the first round ( 2 years) exports are left fairly untouched (not shown). Since, however, firms do not lower their domestic prices (before value-added tax) by the full amount of the value-added tax rate change, they gain initially on the profit margin side. This is quite normal pricing behavior among firms. It is difficult

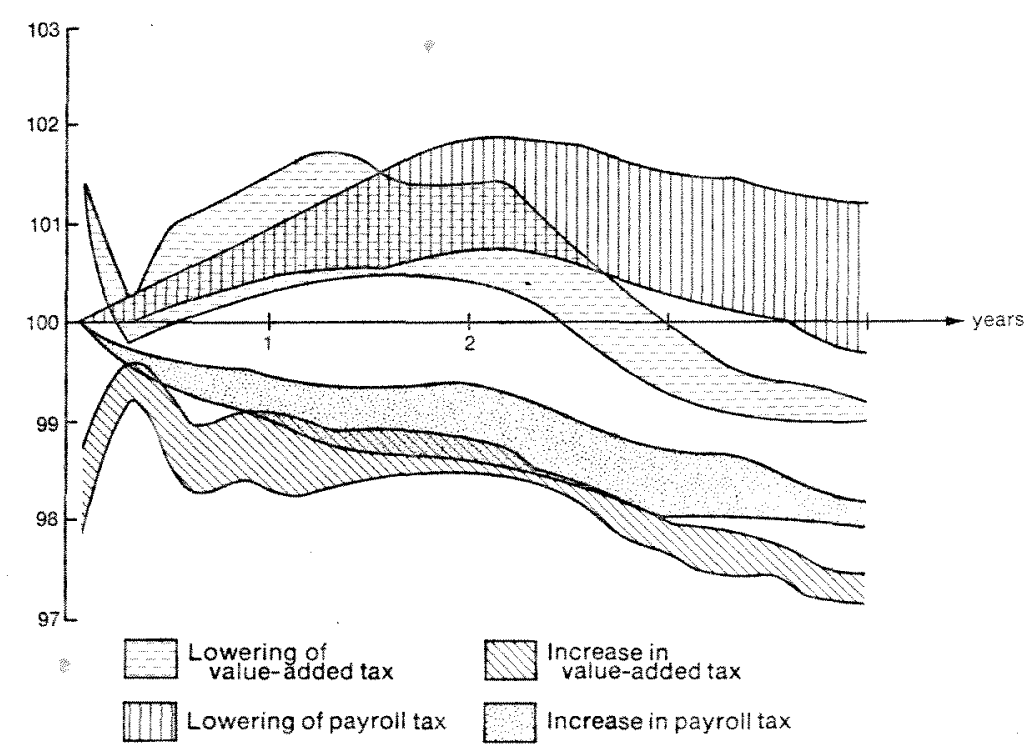

Figure 2.6. GNP effects of value-added and payroll tax changes. Tax rate changes are up (and down) $2.5 \%$ and $5 \%$ respectively in the value-added tax case. The payroll tax has been increased and decreased so that the fiscal budget impact the first year is approximately the same as for the corresponding value-added tax change. Simulated results are shown as percentage of the corresponding values of the reference case. 
Table 2.2

Sensitivity Analysis with Value-added and Payroll Taxes

\begin{tabular}{|c|c|c|c|c|c|c|c|c|c|c|c|c|c|c|c|}
\hline & \multicolumn{2}{|c|}{ GNP } & \multicolumn{2}{|c|}{$\begin{array}{c}\text { Industrial } \\
\text { Output }(O)\end{array}$} & \multicolumn{3}{|c|}{ Industrial Employment $(L)$} & \multicolumn{2}{|c|}{$C P I$} & \multicolumn{2}{|c|}{$\begin{array}{c}\text { Producer } \\
\text { Prices }(P D O M) \\
\end{array}$} & \multicolumn{2}{|c|}{ Wage Costs $(W)$} & \multicolumn{2}{|c|}{$\begin{array}{c}\text { Profit Margins } \\
(M) \\
\end{array}$} \\
\hline & $\begin{array}{l}1969- \\
1970 \\
\end{array}$ & $\begin{array}{r}1969- \\
1975 \\
\end{array}$ & $\begin{array}{r}1969 \\
1970 \\
\end{array}$ & $\begin{array}{r}1969- \\
1975 \\
\end{array}$ & $\begin{array}{l}1969- \\
1970 \\
\end{array}$ & $\begin{array}{l}1969- \\
1975 \\
\end{array}$ & Year 7 & $\begin{array}{r}1969- \\
1970 \\
\end{array}$ & $\begin{array}{l}1969- \\
1975 \\
\end{array}$ & $\begin{array}{r}1969- \\
1970 \\
\end{array}$ & $\begin{array}{c}1969- \\
1975 \\
\end{array}$ & $\begin{array}{l}1969- \\
1970 \\
\end{array}$ & $\begin{array}{l}1969- \\
1975 \\
\end{array}$ & $\begin{array}{r}1969- \\
1970 \\
\end{array}$ & $\begin{array}{l}1969- \\
1975 \\
\end{array}$ \\
\hline \multicolumn{16}{|l|}{$V A T A X$} \\
\hline$+5^{a}$ & 98.5 & 97.5 & 98.4 & 97.6 & 98.1 & 97.8 & 100.1 & 104.6 & 104.4 & 105.3 & 106.0 & 100.1 & 94.4 & 100.6 & 109.3 \\
\hline 5 & 101.3 & 98.6 & 100.6 & 96.6 & 93.3 & 92.4 & 100.0 & 96.6 & 95.5 & 98.2 & 95.8 & 100.1 & 88.9 & 116.4 & 125.5 \\
\hline \multicolumn{16}{|c|}{$W T A X^{-\infty}$} \\
\hline$+5^{a}$ & 99.2 & 98.2 & 99.2 & 98.4 & 99.6 & 98.4 & 100.1 & 99.6 & 99.5 & 99.7 & 99.1 & 100.0 & 95.4 & 98.3 & 106.1 \\
\hline $5^{a}$ & 101.0 & 101.2 & 101.0 & 100.9 & 100.3 & 100.7 & 100.0 & 100.3 & 100.3 & 100.5 & 100.8 & 100.0 & 99.6 & 102.1 & 102.0 \\
\hline
\end{tabular}

Note:

$W=$ Labor cost to firm (wages + all social charges incl. $\quad R S A V H=$ Household savings ratio out of disposable income supplementary pension charge)

$I N V F I X=$ Investment in industry in constant prices

$P D O M=$ Domestic wholesale prices, industrial goods, incl.

$$
\text { of VATAX }
$$

$V A T A X=$ Value-added tax (money terms)

$I T A X=$ Income tax, income earners (money terms)

$M=$ Operating gross profit margin

$C P I=$ Consumer price index, incl. of VATAX

$P R O D=$ Average labor productivity

$Q=$ Industrial output

WTAX = Payroll tax including all social charges and ATP-charge (money terms)

GNP $=$ GNP

$T X V A$

$L=$ Labor input in industry; effective man-hours

$T X I=$ The corresponding nominal rates

$T \times W$

If nothing else is aid, all tables and figures are on index from where the endogenous variable reported $(O P R O D$, etc.) is indexed with the reference run as the base. On a current basis: If $Q(1972)=3.363$ in the reference run and $Q(1972)=3.681$ in the experimental run, the index will say index $=3681 / 3363 \times 100=109.5$ (Diagrams). On an average basis: The indexes have been averaged from the beginning year 1969 to the year you read in the table.

\footnotetext{
a The payroll (WTAX) change has been graded so as to correspond to the corresponding value-added tax changes the first quarter.
} 
to compensate for the tax by raising prices fast, and firms only reluctantly lower prices by the full amount of the reduction in the tax. This produces an assymmetrical profit response to value-added tax rate changes for the 7-year period of investigation that is supported by knowledge of firm pricing behavior. The higher price level (after $\operatorname{tax}$ ) can be maintained for some time, and firms gain on selling more at home and relatively less in foreign markets. Export performance is coming down slowly from the third year and even though savings also decrease, the import effect persists. More import price competition hurts business profits, and firms begin to get tough on the wage side to satisfy their profit targets. The net impact is a worsened external balance, less domestic supplies in domestic markets (compared to the reference case) and a slowdown in industrial growth. Employment and real wages suffer in the medium term, but business profit margins are still maintained at a higher level at the end of the 7-year period, so the results correspond to quite rational responses on their part. We should note here that profit margins are on their way down strongly in 1975 , probably to undershoot the reference case after a few years. This again underlines the new realistic and hence important feature of disequilibrium models of this kind. Depending upon initial conditions and the time period studied, the results may be very different. The possibility that the incidence and the allocation effects of changes in, for example, payroll tax rates may be very different depending on the cyclical situation is also emphasized in Normann and Sodersten $(1978$, pp. 65 f). A deflationary spiral sets in from the fourth year that works counter to the initial fiscal measure. Firms come out all right with higher profit margins, but output suffers slightly. This deflationary cycle is just about to reverse itself at the end of the 7-year period. Note, also, that employment recovers faster than output, and the reason of course is a lowering of real wages.

The back side of this situation is a lower productivity growth than in the reference case. Quite in keeping with the dominant property of our model system, this dynamic reversal effect is stronger and faster the larger the initial parameter change. The reason is that the early overoptimism generated by the fiscal stimulant has

created overexpansive output and recruitment plans. Since profit targets are based on excessive price and sales expectations, wage drift was allowed to occur without violating $e x$ ante targets. Firms then experienced profit disappointments ex post and are consolidating their positions by releasing labor and pushing up profit margins at lower output levels. This is what normally happens in the early phases of a business recession, so in fact the initial boom created by the fiscal stimulus has generated its own "extra" slump after a few years, albeit a minor one.

These results may seem surprising to a reader more used to work with less dynamic macro models. The results reported on, however, only tell that growth is not the only way to maintain rates of return for firms, and when markets are not so competitive and when profits come easily, it may be better to slow down investment and growth. These results depend in part on the degree of competition in markets but also in part on the feedback, profit-targeting device (maintain or improve profits-MIP) in the firm model. As a result of improved profit performance, firms upgrade their targets and vice versa. This set of propositions is difficult to test owing to the long time dimension involved, but one has to remember at the same time that these unconventional results are conventionally assumed away in many econometric models. So there is no need to question the results except on empirical evidence to the contrary. A case in point here is Pratten's (1976) results from comparisons of matched Swedish and British firms. He found that while British firms were far below their Swedish counterparts in productivity and growth rates, they maintained systematically higher rates of return.

Again note (from Figure 2.6) the second quarter temporary reversal of the GNP effects. It depends partly on the fact that households do not adjust their consumption immediately to their lower or higher real purchasing power; they prefer to take part of the adjustment by way of their savings account. 
Payroll Tax

We then raised and lowered the payroll $\operatorname{tax}^{27}(T X W)$ by as many percentage points as needed to make the initial budget effect in the first quarter 1969 for the public sector equal to that in the value-added tax change above for each of the four cases in the table. This step change was then maintained as a percentage difference for the rest of the period, as in the earlier experiments.

This time the activity-level effects look more familiar. An increase in the payroll tax produces a negative output effect that tends to increase slowly over the experimental period. A lowering of the payroll tax produces a small but persistent plus effect on output. However, toward the end of the period, the process is beginning to reverse itself under the ceteris paribus assumption, and the gain is quite small in year 7 .

Increasing the payroll tax without running up public expenditures simultaneously exercises a slight restraint on domestic prices, and the effect is the opposite when the tax is lowered. The initial effect on wage costs is nil in the sense that practically all the effect carries over to income earners in the form of lowered cash payments and very little carries forward to prices. Over the 7-year run wage costs are, however, further reduced relative to the reference case owing to a slowdown in economic growth but not in the inflation rate. These results may seem somewhat surprising considering earlier discussion of the incidence.

We should recall, however, that there is no assumption to guarantee this almost complete backward shifting of the payroll tax change to wages. The key assumption is that firms are keen on meeting their profit targets and do not bid up wage costs inclusive of payroll taxes to violate these targets. The uncertain element is to what extent profit target maintenance is enforced each period. We do not yet know. This is an empirical issue that relates to the specification of one of the crucial time reaction parameters $\left(X^{3}\right)$ mentioned in the model section. Available evidence (see below) suggests that a slight relaxation of the enforcement rate should be entered.

Business profit margins increase initially from a lowering of the payroll tax, owing to the positive output effect at no change in wage cost. Firms then strive to maintain these margins successfully. At the somewhat higher price level, and a slightly lowered output volume, real wages decrease over the 7-year period. Hence a lowering of the payroll tax seems capable of generating a very small growth effect through a slight increase in profit margins and investment.

On the other hand, raising the payroll tax seems to give rise to both faster and somewhat larger negative effects on output at no price increases, since the tax is shifted to wage earners quite fast again. The price level in fact comes down somewhat in the 7-year run. Even though business profits suffer initially, firms react strongly to counter this effect, and the long-term influence is higher rather than lower profit margins. This profit margin increase takes its time to generate more growth and employment through investment, and employment has just about recovered from the initial decrease in year 7 . Again these results emerge under the assumption that the public sector does not use up its increased income by spending more. (See, however, below, when we move the payroll and value-added tax rate equally, but in opposing directions.)

${ }^{27}$ Note here that we have a very broad definition of the payroll tax. It includes all social charges together with the supplementary pension fee (the ATP charge) on total wayes and salaries. The public sector is defined accordingly, making the supplementary pension system part of the government budget. However, to keep detail within limits we have allowed a misspecification to slip in. Public transfer payments to households are taxed as income, and this is not $100 \%$ correct. Since this is so in both the reference and the experimental runs, the difference is not more than marginally affected. 
The ways firms set and respond to their profit targets obviously are instrumental in producing the longer-term reversal of the initial effects that take place when policy creates a stimulus. In principle we believe that we have a very realistic specification of the operational functioning of profits in an economy. However, the profit-targeting device is also instrumental in producing the very fast carry over (backwards) of payroll tax changes to wages and no carry-forward to prices at all. In the long run this is compatible with the results of Brittain (1972) and Vroman (1974) but not with those of Leuthold (1975), who argues on the basis of U.S. data that the short-term incidence is not $100 \%$ on wage earners. Weitenberg (1969) finally reports (on the basis of a Duch Central Planning Bureau model) that the mediumterm incidence is all on wage eamers but partly through backward shifting and partly through forward shifting to prices. We know from other empirical tests of the model that with the numerical specifications used here firms seem to be too fast and rational in pushing their profits up against their targets, so the incompatibility with the above-mentioned empirical results should rather be taken as a suggestion that further experimentation, checks, and fine-tuning of the model are needed on the short-term response before we can say that we know.

Finally note from Figure 2.6 that even though the average GNP effects over time are roughly the same, the quite different economic mechanisms at work generate different time profiles.

As a final check on the model we have rerun it with and without the temporary lowering of the value-added tax 2 nd and 3 rd quarters 1974 by 3 percentage points. Table 2.3 shows the effects on some macro variables. We note that the shortterm GNP effect is of roughly the same magnitude as calculated elsewhere at the time of the real tax experiment. Even though the value-added tax is increased back again to the earlier level after 2 quarters, the output and employment effects do not cancel over the 2 -year period. The price level effect in both directions is, however, almost simultaneous to the parameter change.

\section{Substantial Modifications of the Swedish Tax System and Their Economic Effects}

In the earlier sections we have analyzed the economic effects of differently sized countercyclical, fiscal parameter variations. In this section we are interested in the effects of a sizable modification of the tax system. Since the model runs on a market-price information-response system, where performance of the total economic system depends on the ability of agents (decision makers) to interpret these signals, we have to make major fiscal changes in a gradual way. Even so we should expect some economic effects of a negative nature to depend on disturbances in the infor-

Table 2.3

Effect of Temporary Lowering of Value-added Tax by 3 Percentage Points, 2nd and 3rd Quarters 1974

\begin{tabular}{|c|c|c|c|c|c|}
\hline & After 2 & 4 & 8 & 12 & quarters \\
\hline GNPa & 0 & +0.3 & +0.2 & +0.3 & Percentage points higher \\
\hline Industrial employment & 0 & +0.4 & +0.1 & +0.2 & Percentage points higher \\
\hline $\begin{array}{l}\text { Consumer price index (CPI) } \\
\text { (incl. value added tax) }\end{array}$ & -3 & -0.1 & -0.1 & -0.1 & Percentage points lower \\
\hline
\end{tabular}


mation system which demand a long time to leam and to correct for. This, no doubt, is a very relevant aspect of the problem we are about to study. ${ }^{28}$

\section{Value-added and Payroll Taxes}

We first have to look at a relatively minor shift in emphasis from a payroll to a value-added systen (Table $2.4 \mathrm{~B}$ ) and vice versa (Table $2.4 \mathrm{~A}$ ). The experiment has been designed as a once-and-for-all change in 1969, graded so as to leave the total tax take of the public sector unchanged for the first period (=1 quarter in 1969).

The relative speed of transmission of the incidence between the two tax types when moving from payroll toward more value-added taxes means that real purchasing power of the household-i.e., real wage costs to firms after payroll, income, and value-added tax-first increases and then decreases relative to the reference case. Over the entire period there is a sight increase in real (after all taxes) wages (103.8/ $102.7 \approx 1.01$ ) and vice versa moving in the opposite direction. It may be of interest to notice (Table $2.4 \mathrm{~A}$ ) that this time a somewhat different incidence pattem emerges compared to the earlier sensitivity analysis. There is now a net of VATAX producer price increase which in this case must be interpreted as a carry-forward incidence of the payroll tax. Also long-term wage costs increase. Just about the reverse happens when the tax change goes the opposite way (Table 2.4B), and these results are more in keeping with the empirical results referred to above.

Altogether the simulations so far suggest that there are no rules of thumb to tell beforehand to what extent the income earner carries the burden of or benefits from a tax change, when we allow for all interactions through taxes in a total economic system like this model. (There is a farly high probability that the simulations of reality are more complex.)

There is a slight upward drift in the general price level corrected for tax changes in final prices. However, the nominal wage cost level faced by firms comes down slightly and a small long-term improvement in profit margins occurs. Exports are left roughly unaffected in both the short and the long runs. There is very little longrun change in output and employment levels. Since household saving and business investment decrease, this obviously means an increased efficiency in the utilization of capital resources and an increase in rates of return.

As this is being written, the monetary system has not yet been integrated into the model. This means that the domestic rate of interest has been entered exogenously with the same values in the experiment and in the reference case. The adjust ment of the interest rate and the consequent inancial fows due to lowered household saving and business investment spending has not been allowed to work itself properly through the entire economic system. One would expect monetary feedback here. It is at present impossible to say how large this feedback will be. We will have to leave this problem open, as most other students who have examined it have done. Since all cash flows associated with real transactions have been $100 \%$ booked, we know, in an accounting sense, that whatever is not invested accumulates as idle financial balances. What is gained in efficiency in the business sector idles away at no use elsewhere.

${ }^{28}$ Individual decision makers (firms) in the model are equipped with a feedback learning mechanism for all their expectational signals that correct the interpretation of "new" signals asymptotically but quite fast. (See earlier description of micro part of modet.) Very erratic disturbances that go on forever cannot be interpreted, however, and by definition the inteligibil. ity of the market signaling system will then also be left forever in more or less disorder. However, if the change to a new system is smooth and means a steady and interpretable experience, the rules of interpretation can be learned. We can then isolate the economic effects of the transition if we run the simulations long enough. We have not done that, because of time constraints and also because we then have to leave the domain of known historical experience (1969-1975) and interpret our results in a new, hy pothetical economic environment. This is by no means easy. 
Table 2.4

"Budget Neutral" Changes between Payroll and Value-added Tax Systems

\begin{tabular}{|c|c|c|c|c|c|c|}
\hline & \multicolumn{2}{|c|}{$\begin{array}{c}A \\
\text { Toward More Payroll Tax } \\
\text { (TWX up } 0.05 \text { and TXVA down } \\
0.03 \text { in 1969) }\end{array}$} & \multicolumn{2}{|c|}{$\begin{array}{c}\text { Toward More Value-added Tax } \\
\text { (Vice versa) }\end{array}$} & \multicolumn{2}{|c|}{$\begin{array}{c}C \\
\text { Value-added Tax Replaces } \\
\text { Entire Payroll Tax, over } \\
\text { 5-Year Period } 1969-1974\end{array}$} \\
\hline & Average $1969-70$ & Average 1969-75 & Average $1969-70$ & Average 1969-75 & Average $1969-70$ & Average 1969-75 \\
\hline$W^{\prime}$ cost to firm & 100.8 & 101.6 & 100.1 & 98.8 & 100.0 & 101.8 \\
\hline Take home $W$ & 95.7 & 96.5 & 105.1 & 103.8 & 104.2 & 115.5 \\
\hline PDOM & 99.5 & 100.2 & 103.8 & 104.1 & 101.4 & 107.7 \\
\hline \multicolumn{7}{|l|}{$\begin{array}{l}\text { PDOM net of } \\
\qquad V A T A X \text { (to firm) }\end{array}$} \\
\hline$M$ & 104.5 & 104.0 & 99.8 & 101.5 & 98.2 & 99.0 \\
\hline$C P I$ & 98.2 & 98.7 & 102.9 & 102.7 & 101.2 & 106.2 \\
\hline CPI net of VATAX & 100.2 & 101.7 & 99.9 & 99.7 & 99.8 & 100.4 \\
\hline$P R O D$ & 100.1 & 99.0 & 100.5 & 99.5 & 99.6 & 100.5 \\
\hline$Q$ & 100.3 & 100.3 & 98.8 & 99.6 & 100.2 & 99.9 \\
\hline$G P^{\prime}$ & 100.9 & 101.0 & 98.8 & 98.7 & 100.0 & 100.1 \\
\hline$L$ & 100.0 & 101.3 & 98.4 & 100.0 & 100.6 & 99.4 \\
\hline$R S A V H$ & 126.7 & 109.5 & 68.3 & 91.3 & 143.3 & 119.0 \\
\hline INVFIX & 110.0 & & 106.9 & & 100.5 & 94.1 \\
\hline EXPORTS & 99.7 & 96.5 & 99.1 & 100.0 & 100.2 & 100.0 \\
\hline \multicolumn{7}{|l|}{ Sector Effects $(Q)$} \\
\hline RAW (1) & 99.8 & 100.0 & 99.1 & 101.0 & 99.9 & 100.6 \\
\hline IMED (2) & 100.0 & 99.2 & 99.5 & 99.8 & 100.1 & 99.7 \\
\hline DUR (3) & 99.9 & 98.1 & 99.0 & 99.8 & 100.4 & 100.6 \\
\hline NDUR (4) & 101.1 & 103.2 & 97.0 & 98.0 & 100.0 & 98.9 \\
\hline
\end{tabular}

Note: For explanation of the scaling see Table 2.2

${ }^{a}$ Parameter change determined so that fiscal neutrality obtained first period (quarter) in $\mathrm{A}$ and $\mathrm{B}$ and approximately obtained for 5 -year period in C. For all remaining periods, differences in the total public tax intake depend on changes in the various tax bases caused by the parameter changes. 
The case is just about reversed when we shift emphasis from the value-added tax toward the payroll tax (Table $2.4 \mathrm{~A}$ ). A slight lowering of real wages, a slight increase in volumes $(Q, G N P$, and $L)$, more saving and more investment in business take place. Again, as in the reversed case, however, profit margins increase, and this time somewhat more. Note that both the price (PDOM) and profit-margin effects take place during the first two years and are then maintained.

The export effect is not symmetrical. Only in this case there is a slow, longterm decrease of expected direction. We noted earlier that feedback effects via foreign trade tended to affect domestic activity levels.

The extra expansion in output is less than what one would expect from the extra investment increase. Rather than piling up idle money balances, this time idle capacity increases in the business sector, and rates of return do not increase. Again this indicates that a money system should have had a chance to exercise a balancing effect here through interest rates. Compared to the United States, however, the Swedish credit market does not perform in any prominent way as a market when it comes to allocating resources (Teigen, 1976). So this result (as well as the opposite one above) should in no way be considered empirically wrong a priori.

When we now turn to a complete replacement of the payroll tax system with a value-added tax system over a five-year period, we are engineering a very smooth transition (Table $2.4 \mathrm{C}$ ). The experiment is roughly controlled in the sense that the public budget and deficit (surplus) is only affected in a minor way throughout the 5 -year transition period. Even though a substantial change occurs in the long run, one should recognize that each of the annual changes (steps) taken are smaller than the once-and-for-all changes in the earlier two experiments. Hence, the individual disturbances generated in markets are smaller this time. This is quite in keeping with a persistent property of our model. It tells us that rough policy treatment of the economy might generate adverse effects. It also suggests that the grading of a substantial institutional change may be important, since if it is done in a nice and smooth way, decision makers in the markets get a chance to learn how to reinterpret the signals.

The effects on price and wage level are more pronounced, but the substantial institutional change generates no major economic disturbances. Activity levels, besides some small short-term turbulence (not shown) is left roughly unchanged over the 7 -year period. This effect of course depends on the approximately unchanged

budget position of the public sector. The reversed replacement (from value-added to payroll tax, not shown) yields perfectly symmetrical results almost throughout.

The only surprise is that compared to the small fiscal change in Table 2.4A and $\mathrm{B}$, household saving this time responds in an opposite and expected way. The changeover to a value-added tax system, taking away the payroll tax, stimulates saving. And this is what we should expect, since household saving is now left untaxed. We note again, however, that increased household saving does not generate more investment volume in industry. It is not needed, since output is left unchanged. Furthermore profit margins slide down a bit.

The increased household savings rate depends on the ambition of households to maintain real-transactions cash balances because of the higher inflation and wage rates. The increased savings accumulate in the monetary system for some use that we do not know in the present version of the model. 


\section{Structural Effects of General Fiscal Parameter Changes}

We know intuitively that no general policy measure can be enacted in a structurally heterogenous economy leaving the structure unchanged. Conventional macro models of whatever type normally do not lend themselves easily to the analysis of such effects. To us a definition of structural change would be in terms of micro firm units and imply that the coefficients in a "corresponding" macro relationship, say a production or investment function, would not remain unchanged over time. Underneath this variability one would find a changing size distribution among firms or a shift in rate of return, investment, and growth relationships of such a nature that the aggregation assumptions that underlie the macro model would vary with the experimental design. In this context we will, however, have to limit ourselves to a few comments on and illustrations of the changes in relative sectoral sizes brought about by the above fiscal parameter changes via relative changes in price and rate of return among individual firms in the markets. Again we confine ourselves to a 7-year time span. To discern any sectoral effects we need fairly strong and, as it turns out, sudden parameter changes. We can of course discuss at length what is required for a policy change to be general. We will find that there are no true measures. Every possible one is selective in one way or another. The value-added tax hits the households (we believe), and the payroll tax hits the firms, and so on. Such parameter changes are, however, conventionally called "general" and we will do so as well.)

This time we are interested in how the effects of one "general measure" are carried through the economic system, but not between various broadly defined macro aggregates (out put, CPI, wages, profits, etc.). Rather we want to see how the whole carry-over (or through) process diversifies unevenly between firms and subproduction sectors. It should also be of interest to study and discuss how much of this selective impact between sectors depends on the degree of "selectivity" that affects the parameter change although this would take us too far in this context. One could easily imagine, for instance, that a change from a value-added tax to a payroll tax system is apt to hurt (or help) consumer goods producers more than other sectors. But no one knows for sure.

One thing is clear from Table 2.4. When we make a sudden, once-and-for-all change from a payroll tax system to a value-added tax system, it hits household demand. As a consequence, growth comes down in the consumption goods sector (4) and increases in the typical export sectors. This relative growth reallocation between sectors is, of course, reinforced by the fact that invesiment spending also decreases somewhat, and as a consequence total industrial out put growth decreases as well.

When the tax system is changed in the other direction, the effects are also reversed. This time the differential impact "looks" somewhat bigger in the table, since the positive saving-investment growth effect combines with the direct consumption effects to favor growth in the consumer goods sector.

However, one should note that raised demand in domestic households as well as raised investment demand is partly at the expense of export deliveries. In the beginning, imports increase, as should be expected, and the foreign balance deteriorates (not shown). In the longer term both exports and imports balance off better in the downward direction compared to the reference case, but the long-term outcome is a worsened external balance. 
Lower payroll taxes and a higher value-added tax as compensation, however, mean a long-term improvement in the extemal balance, even though both exports and imports decrease for the first few years.

Interestingly enough, however, when we allow for a smooth gradual replacement of the entire payroll tax system by a more dominant value-added tax system (Table 2.4 and Figure 2.7) we can study reactions of similar direction during the seven-year period. But the internal dynamics of the system this time are efficient enough to make relative prices and activity levels interact in such a way that the initial relative price structure is approximately restored toward the end of the simulation run and so is industrial structure, as measured by relative growth rates in output. Again, we should remember that if actors in the markets are allowed enough time to reinterpret the new signals, no adverse effect on total growth need occur. The longterm effect on the structure of the value-added and payroll tax switch seems to be fairly "neutral". 29

When the direction of fiscal change is revised (the payroll tax gradually replaces the value-added tax) the effects mentioned above are also reversed (see Figure 2.7). It is worth noting that the combined effect on household durable goods demand and business investment goods demand (both goods categories being supplied by sector 3 in Figure 2.7) is slightly positive on the average when going from payroll to a value-added tax system and vice versa. Furthermore, when the effect is negative, the cyclical swings generated in the durable goods producing sectors are much stronger. And, since the effect on total industrial production for the same period (the fiscal change going both ways) is approximately nil, part of the explanation lies in a reshuffling of investment spending patterns between firms and sectors. None of these results are a priori obvious but depend on the numerical specifications of the model.

We note that the changes in growth rates are quite small despite the large institutional change, and that initial sectoral balance is roughly restored by the end of the 7-year period. Furthermore, foreign trade plays an important role in the adjustment process, as witnessed by the opposite movements of the export sector 1 (raw materials) and the domestically oriented nondurable, consumer goods sector 4 . The two effects roughly cancel over time, and movements are in opposing directions and depend upon the direction of the fiscal change.

Figure 2.8 finally, gives a micro illustration from a new experiment clarifying what takes place within the model. We have chosen to raise transfer payments to households and the payroll tax simultaneously in 1969 so that the initial (1969) public budgetary impact is approximately nil. ${ }^{30}$ The expected change would be a shift in total consumption demand towards relatively more private consumption. Domestic producers of consumption goods would benefit, and typical export sectors would be hurt. How exactly business investment spending is affected cannot be foretold by simple reasoning. Since the fiscal parameter change is sudden, substantial, and of a one-shot type, we expect a negative total growth effect over the sevenyear period owing to market disturbances. This conclusion is on the basis of our experience from interpreting Tables 2.2 and 2.4 . This would suggest less investment spending, but perhaps more household spending on durable goods. Increasing transfer payments while increasing the payroll tax, however, is very similar to lowering the value-added and increasing the payroll tax. Tables 2.3 and 2.4 would thus suggest slightly more investment and hence more growth in sector 3 .

${ }^{29}$ We should note in this context that the foreign relative price spectrum is the same in all experiments, and the govemment and households fo not change their demand pattervex cept through endogenous feedback by the fiscal parameter dianges.

${ }^{30}$ And so that each opposing parameter change roughly corresponds to a change in the value-added tax rate of 5 percentage points (see Table 2.2). 


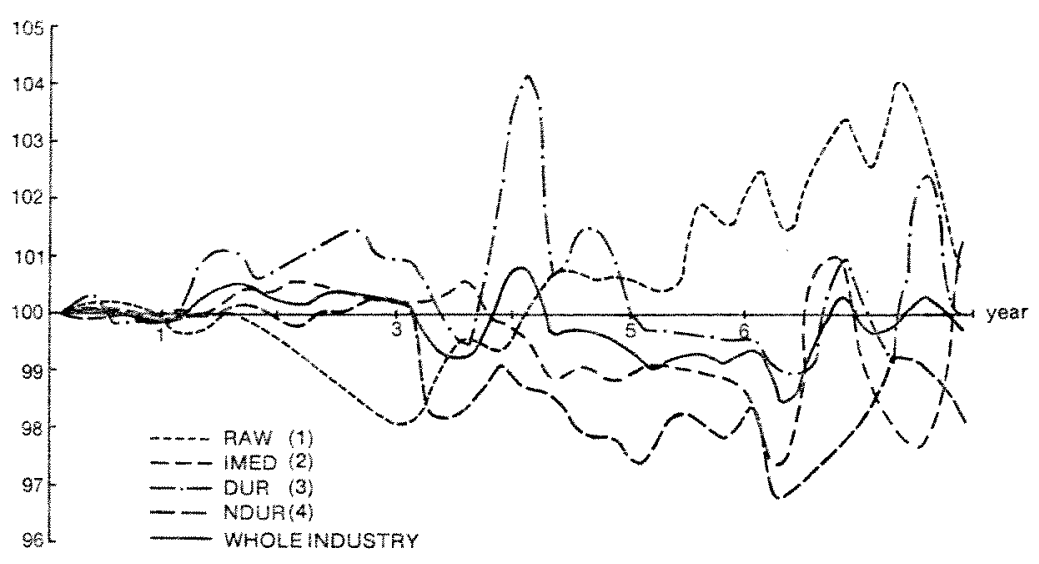

Simulated results as percentage of reference case.



Simulated result as percentage of reference case.

From value-added to pavroll tax.

Figure 2.7. Sector effects on industrial output of complete change of tax over 5-year period. (See Table 2.4.)

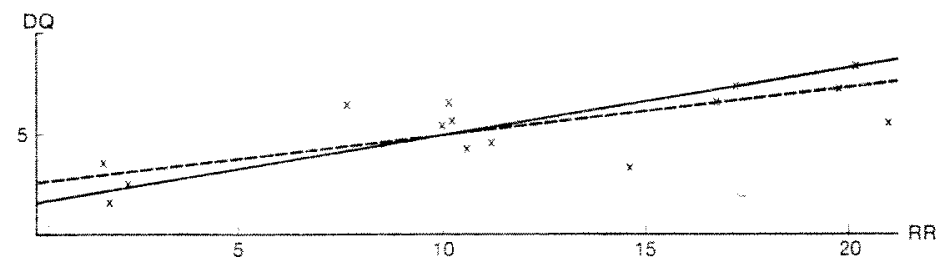

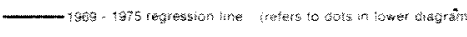

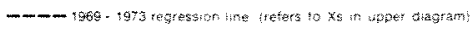

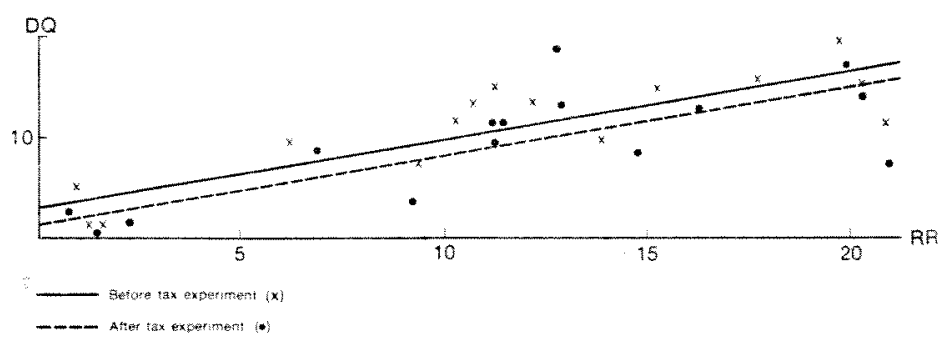

Figure 2.8. Relationship between rates of return $(R R)$ and growth in output $(D Q)$ of individual firms in the market. The upper graph is a comparison between periods 1969-1973 and 1969-1975, 5- and 7-year averages respectively. The lower graph covers the period 1969-1975, before and after combined transfer payments (to households) and payroll tax change. 
The outcome is not exactly as anticipated. Over the 7 -year period both the raw materials sector and the investment and consumer goods sectors lose growth on the average, as a result of the fiscal change. For raw materials producers this would be considered normal as they export the bulk of their output. They do not benefit indirectly from the transfer payment to households, but are nevertheless affected by the payroll tax increase. For investment goods producers output decreases slightly, although earlier results suggest a slight demand benefit. For consumer goods the result is odd at first sight. The result is, however, due to the fact that firms respond fast to the payroll tax increase by reducing cash wage payments after payroll tax, so the net effect on disposable income (after tax and transfer payments), everything considered, is a reduction.

Figure 2.8 illustrates what has happened at the micro level for the investment goods sector. The upper scatter and dashed line in Figure 2.8 give the relationship between average rates of return and output growth rates for the five-year period 1969-1973. There is a fairly strong relationship, as should be expected. When the same relationship is extended to 1975 , the regression line (shown by the solid line in the upper and the dashed line in the lower part of the figure) pivots for two reasons. The high-performance (in terms of profitability) firms essentially stay with their relatively higher rates of return for the longer period. Since they reached that position in the inflationary period $1972-1973$ and have plowed back profits in investment, and/or have borrowed more to invest because of the higher rate of return, the higher growth in capacity that occurs with a delay explains part of the pivoting. However, some of the firms in the low-performance end have suffered instead, owing to the wage drift induced by the generally higher inflation rate that they have to share. This reinforces the pivoting in the left-hand end of the diagram. The discriminating impact on firms in different performance brackets of sudden inflation bursts (1973 and 1974) followed by a sudden lowering of price increases (1975) is illustrated even better in Figure 2.9. The reason is that wage drift is governed by a margin of high-performance firms but spreads to all firms through the labor market. Highperformance firms bid up wages to get more people to improve their profit position, so arrows above $10 \%$ rates of return in Figure 9.9 tend to go up and right. Low. performance firms have to take these wage increases in order not to lose people, and their rate-of-return position deteriorates. Arrows point upward and left in Figure 2.9 .

When the fiscal change defined above is enacted, the effect is to shift down the whole cluster of $(R R, D Q)$ points in Figure 2.8 (lower diagram) relative to what it would have been without the change. The same average rate of return for the $1969-1975$ period is now associated with a lower average growth rate. The shift is in both dimensions, however, and the fiscal measure enacted both lowers the average growth rate for the sector and increases the rate of return. The reason is again indirectly clear from Figures 2.8 and 2.9. The two fiscal measures combined shift the composition of demand suddenly. Some firms are hurt and slow down their investment spending. Others benefit, but there is not time enough to catch up fully during the period, and total growth is lowered.

\section{CONCLUSIONS AND PLANS FOR THE FUTURE}

The analytical work performed so far on the total model system can be said to have produced an integrated picture of a total economy in operation that in some ways differs from what is conventionally believed. Among these effects are the seemingly different short-term and long-term responses of the entire model economy to a set of parameter changes. Other unusual effects are the responses of the system to disturbances in information signaling at the micro market level. Many of the effects mentioned have been suggested as empirically relevant in literature, 


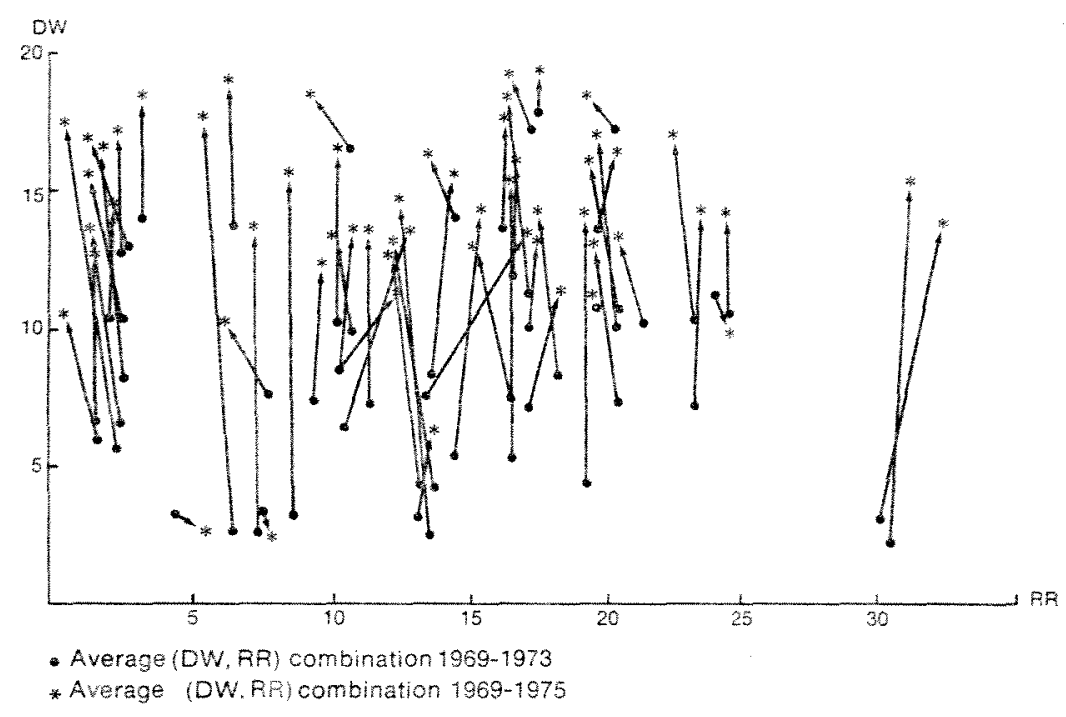

Figure 2.9. Rates of change in nominal wage costs to firms (DW) and real rates of return $(R R)$ after inflationary period in investment goods sector. Arrows bind together individual firms and indicate directions of change.

but to my knowledge this spectrum of features has not been brought together in one explicit model system elsewhere. The core mechanisms that cause them to operate here are the explicit markets that integrate the micro (firm) and macro levels. Several of these properties have been illustrated in the tax experiments reported in this paper.

These results are of course highly conjectural. We have not yet been able to test and check the entire model to the extent that would make us willing to express ourselves with the confidence that is commonly displayed when results are reported from econometric models. The results that we have chosen to report, however, are such that we expect them to be able to weather quite well further testing by ourselves and others. In fact, further testing-or calibration-of the model system is the key word in our plans for the future.

The model system that we currently have consists of a series of moro or less a state of constant change. The most immediate plans call for calibrating the latest version with the monetary system and programming a long-term investment-financing system. No additional calibration will be needed, since this new module will be used only for some model firms with which we establish a direct interface between real firms and the model system. These firms will then supply their own data.

After this, it will be necessary to halt further mathematical development temporarily to allow the model to stabilize and us to understand its mathematical prop. erties better.

The data base and the parameter set still lack precision and quality in many important places (especially on the micro side), and the most important task after completion of the above model specification stages will be to improve and complete the data-base work.

Parallel with this we will start up a series of application experiments studying inter alia

inter alia labor market mobility, wage setting, and economic growth; the effects on economic structure of relative price changes; The Keynesian-Monetarist controversy over growth and inflation; and the long-term effects on the Swedish economy of the massive subsidizing of firms in distress that is currently going on.

After this work has been done, we will decide to what extent it is worth while to improve further on the model's specifications. 